\title{
Factors affecting the suitability of superplasticiser-amended cement for the encapsulation of radioactive waste
}

\author{
Matthew Isaacs \\ Department of Chemistry, University of Surrey, Guildford, UK \\ John Hinchliff \\ JH Consulting, Newark, UK \\ Monica Felipe-Sotelo \\ Department of Chemistry, University of Surrey, Guildford, UK
}

David Read

Department of Chemistry, University of Surrey, Guildford, UK; National Physical Laboratory, Teddington, UK (corresponding author: d.read@surrey.ac.uk)

Organic superplasticisers improve the flow properties of cement, offering operational advantages for the disposal of radioactive wastes. However, there are concerns that they could increase the mobility of encapsulated contaminants significantly. The effect of polycarboxylate ether superplasticisers on the solubility of Ni(II), Am(III), Pu(IV) and U(VI) in two cement-equilibrated waters (ordinary Portland cement/pulverised fuel ash (OPC/PFA) and OPC/ground granulated blast-furnace slag (GGBS)) has been assessed. The study included four commercial superplasticisers, three adjuncts (a de-foaming agent, biocide and viscosity modifier) and a bespoke, synthesised superplasticiser from which residual monomer had been removed by dialysis. The commercial products $(0.5 \% \mathrm{w} / \mathrm{w}$ dosage $)$ had a much greater effect on metal solubility than the dialysed equivalent, increasing solubility by 2-3 orders of magnitude. As the adjuncts alone showed no effect, the difference between the commercial and synthesised superplasticisers is attributed to small molecules, primarily residual monomers, in the commercial formulations owing to incomplete polymerisation. The distribution of radionuclides in hardened cement pastes corresponds closely to the distribution of superplasticiser, as shown by ${ }^{14} \mathrm{C}$-labelling in combination with digital autoradiography and accounting for the bleed observed for certain slag-rich formulations.

\section{Introduction}

Low-level radioactive waste (LLW) is defined in the UK as waste that does not exceed $4 \mathrm{GBq} / \mathrm{t}$ of $\alpha$ or $12 \mathrm{GBq} / \mathrm{t}$ of $\beta / \gamma$ activity. Waste classified as intermediate level (ILW) exceeds the upper limit for LLW but does not require heating to be taken into account in the design of storage and/or disposal facilities (Defra et al., 2008). One concept for the geological disposal of low-heat-generating radioactive wastes, encompassing both LLW and ILW, is immobilisation in grouted waste packages surrounded by a cementitious backfill (NDA, 2010a). In a cement-based vault, the persistence of alkaline conditions during the post-closure phase is intended to result in low solubilities for certain radionuclides, limiting the source term for migration by way of the groundwater pathway (NDA, 2010b, 2010c).

The use of cementitious grouts for a variety of wastes is mature and results in passively safe waste packages suitable for long-term management prior to disposal (NDA, 2010a). These grouts typically comprise either ordinary Portland cement/pulverised fuel ash (OPC/PFA) or OPC/ground granulated blast-furnace slag (OPC/GGBS) blends. The addition of superplasticisers (SPs) to the grouts used for waste immobilisation offers operational advantages, including increased fluidity and reduced water content. Additionally, they may be used in the production of concrete waste containers (NDA, 2013).
Different chemical classes of SP have been developed for use in the construction industry, the latest comprising polycarboxylate ethers (PCEs). Although there are clear operational benefits to be gained from using SPs, it is important from a safety case perspective to understand their effect on the longterm behaviour of the encapsulated radioactive inventory. Research has shown that these high-molecular-weight, watermiscible, organic polymers have the potential to both enhance radionuclide solubility (McCrohon and Williams, 1997) and inhibit the uptake and incorporation of radionuclides by the cement matrix (Young et al., 2013). Further, it has been shown that proprietary SPs vary substantially in their complexation behaviour depending on the cement and experimental conditions (Young et al., 2013). Commercial SP formulations may also contain a number of adjuncts, including de-foaming agents, biocides, viscosity modifiers and other impurities, all of which may affect cement pore solution chemistry.

Previous studies on the effect of SP in cement solutions have reported increases in the solubility of $\mathrm{Am}(\mathrm{III}), \mathrm{Pu}(\mathrm{IV}), \mathrm{U}(\mathrm{IV})$ and Tc(IV) of more than two orders of magnitude (Greenfield et al., 1998). These authors attributed the observed increase of solubility to the formation of mixed complexes of the radionuclides with the SP additives stabilised by hydroxyl ions. It has been pointed out that this enhancement may not be realistic since at least $90 \%$ of the SP added to the mix is likely to be retained by the cement matrix (Fujita et al., 2008; Kitamura 
et al., 2013). Moreover, the composition of any organic compound leached from the cement may differ from the bulk SP, as only low-molecular-weight substances, either unreacted monomer or degradation products, could be detected in the pore water (Fujita et al., 2008). Studies undertaken with a commercial PCE (ADVA Cast 551) investigated its effects over a range of concentrations from 0.001 to $1 \%$ cement replacement (Clacher et al., 2011, 2013a, 2013b; Kitamura et al., 2013). These authors carried out ultrafiltration (10 and $30 \mathrm{kDa})$ in order to determine the distribution of $\mathrm{Ni}(\mathrm{II}), \mathrm{Am}$ (III), Th(IV) and U(VI) between the bulk SP and lower molecular weight components of the SP product. Whereas no significant differences were found in $\mathrm{Ni}(\mathrm{II})$ and $\mathrm{Am}$ (III) concentrations between the size fractions, the studies showed a higher proportion of U(VI) in solution associated with the bulk SP. The opposite trend was observed for Th(IV) (Clacher et al., 2013b). These studies illustrate the complexity of SP-cement-radionuclide interactions and the continuing uncertainty surrounding the suitability of SP for radioactive waste encapsulation.

The main objective of the present study is to determine the solubility of several key radioelements (Ni(II), Am(III), $\mathrm{Pu}(\mathrm{IV}), \mathrm{U}(\mathrm{VI})$ ) in solutions containing four commercial SPs and their mobility in SP-amended cements. For the solubility tests, two experimental approaches have been adopted: (a) solubility studies in cement-equilibrated water with subsequent addition of SP in free solution (McCrohon and Williams, 1997) and termed here 'post-addition' and (b) tests in which SP-containing hardened cements are leached and radionuclide solubility tests conducted on the leachate (termed here 'pre-addition'). The terms 'pre-' and 'postaddition' refer to the point at which the SPs encounter the cementitious solution and hence, the sequence in which they interact with the radionuclides of interest. Comparison of the results obtained using the two experimental approaches helps elucidate the degree of interaction between the SP and the cement matrix while providing a more realistic estimate of the effect of SPs on radionuclide solubility under cementitious conditions.

As highlighted by Kitamura et al. (2013), it is not only the concentration of the SP in the cement leachates that affects radionuclide solubility but also their speciation, that is the nature of the organic compounds leached into the pore solutions; this may or may not correspond to the composition of the original SP. Factors to consider are the purity of the SP polymer, potential degradation in high-pH cement pore waters and any adjuncts used to increase workability and shelf life. With respect to the latter, three adjuncts present in commercial products were tested individually to assess their potential influence as complexants. In addition, a bespoke, synthesised PCE comb SP, purified by dialysis to be monomer- and adjunctfree, was subjected to the same tests to shed light on how the purity of the SP products might be a factor in their applicability for radioactive waste encapsulation. A final series of experiments was carried out in which a ${ }^{14} \mathrm{C}$-labelled $\mathrm{SP}$ was added to the cement pastes in order to determine whether the plasticiser has any effect on the amount of bleed water produced and/or inhibits homogeneous uptake of the chosen radionuclides, as suggested by Young et al. (2013).

The work carried out in this paper focuses exclusively on chemical interactions. Owing to the limited activity and heatgenerating capacity of LLW and ILW, the thermal and radiological stability of SP-amended cement was not assessed.

\section{Experimental work}

\section{Materials}

Two cement formulations were investigated, OPC/GGBS (1:9) and OPC/PFA (1:3). The formulations of the grouts used here correspond to the highest cement replacement applied at the Magnox Encapsulation Plant at Sellafield (UK) for ILW; OPC/GGBS from $1: 2 \cdot 33$ to $1: 9$ and OPC/PFA from 1:2.33 to 1:4 (Angus et al., 2010). The GBSS conforms to BS EN 15167-1 regulations for standard construction grade blastfurnace slags (BSI, 2006). The fly ash (referred to in the present work as PFA) and OPC not only comply with the BS EN standards 450-1 (BSI, 2005) and 197-1 (BSI, 2000), respectively, but also with the technical requirements for encapsulation of ILW specified elsewhere (Cann and Orr, 2010). All the cement products were obtained from Hanson Cement Plc. The powders were characterised by X-ray diffraction and loss on ignition (LOI); the data obtained are available in the Supplementary Material (Figure S1 and Table S1).

Four commercial SP products were used for the study, denoted COM1-COM4, as well as three adjuncts; a de-foaming agent, a biocide and a viscosity modifier. The SP products and adjuncts were supplied by Grace Construction Products Ltd. Although the composition of the branded products was not disclosed by the supplier, nuclear magnetic resonance (NMR) and elemental analysis indicate that the adjuncts were organic in nature. Synthesis of a bespoke SP compound, denoted BSP1, was performed using radical co-polymerisation of sodium methacrylate (SM), polyethyleneglycol methylether methacrylate (PEGMA) and methallyl sulfonate (MASA), using sodium persulfate $\left(\mathrm{Na}_{2} \mathrm{~S}_{2} \mathrm{O}_{8}\right)$ as an initiator. All reagents used in the synthesis were purchased from Sigma-Aldrich. ${ }^{14} \mathrm{C}$-labelled SP was synthesised using ${ }^{14} \mathrm{C}$-labelled methacrylic acid and ${ }^{14} \mathrm{C}$-labelled polyethylene glycol (PEG) obtained from American Radiolabelled Chemicals Inc.

Uranyl nitrate $\left(\mathrm{UO}_{2}\left(\mathrm{NO}_{3}\right)_{2}\right)$ and nickel chloride $\left(\mathrm{NiCl}_{2}\right)$. $6 \mathrm{H}_{2} \mathrm{O}$ ) were obtained from $\mathrm{BDH}$ Laboratory Reagents and Sigma-Aldrich, respectively. The radioactive tracers, ${ }^{63} \mathrm{Ni}$, ${ }^{239} \mathrm{Pu}$ and ${ }^{241} \mathrm{Am}$, were supplied by Eckert and Ziegler. 


\section{Experimental procedure}

\section{Superplasticiser synthesis}

Commercially available SPs contain a variety of adjuncts, as well as residues from the polymerisation process. Therefore, a bespoke SP with similar characteristics to the commercial products was synthesised and purified. The polymer, BSP1, was prepared by way of a free radical aqueous polymerisation (Figure S2 in the supplementary material online (Plank et al., 2008)) using SM (1.61 g, 0.0148 mol), PEGMA (4.745 g, $0.00493 \mathrm{~mol})$ and MASA $(0.326 \mathrm{~g}, 0.00197 \mathrm{~mol})$ in deionised water $\left(26 \mathrm{~cm}^{3}\right)$ with sodium persulfate $(0 \cdot 25 \mathrm{~g}, 0.00105 \mathrm{~mol})$ as initiator. The reaction was carried out at $80^{\circ} \mathrm{C}$ for $2 \mathrm{~h}$. The resulting polymer solution was purified using dialysis tubing (MWCO 1200, Sigma Aldrich) to remove unreacted monomers. The dialysis tubing filled with the polymer was placed in deionised water $\left(500 \mathrm{~cm}^{3}\right)$ for $3 \mathrm{~h}$, the water was replaced and dialysis continued for a further $24 \mathrm{~h}$. The solution was collected and the water removed by freeze-drying, yielding a white powder. Effective removal of the monomers was confirmed by analysis of the dialysed product by ${ }^{1} \mathrm{H}-\mathrm{NMR}$. Figure $\mathrm{S} 3$ shows the ${ }^{1} \mathrm{H}-\mathrm{NMR}$ (Bruker 400) spectrum of BSP1 after purification and the commercial COM1-COM4, as provided. The narrow and well-defined multiplets at $7 \cdot 3$ and $7 \cdot 6 \mathrm{ppm}$ in the commercial samples correspond to the characteristic vinylic proton signals of the monomers remaining from the polymerisation reaction (García et al., 2004). These peaks are not observed in the spectrum of the pure polymer. This is due to the polymerisation process in which radicals propagate along the alkene groups of the monomers, breaking them to form new alkane bonds which link the monomers together to form the polymer. The peak at $3.7 \mathrm{ppm}$ corresponds to hydrogen atoms in the PEG chains. This peak appears wider and less well defined in the commercial products due to the fact that polymerisation results in a mixture of PEGMA chains from 200 to $2000 \mathrm{amu}$, whereas only one chain length $\left(M_{\mathrm{n}}=950\right)$ was used for the synthesis of BSP1. The single peaks that appear in the commercial products between 1.8 and $2.5 \mathrm{ppm}$ correspond to unidentified small molecules used as adjuncts. Analysis of the dialysed BSP1 by gel filtration chromatography with refractive index detection showed that the molecular weight distribution of the polymer ranged between 6894 and $11423 \mathrm{~g} / \mathrm{mol}$. Figure S4 illustrates the molecular weight distribution of COM1-COM4 and the purified BSP1 determined by size exclusion chromatography.

\section{Solubility studies}

The solubility of $\mathrm{Ni}(\mathrm{II}), \mathrm{Am}(\mathrm{III}), \mathrm{Pu}(\mathrm{IV})$ and $\mathrm{U}(\mathrm{VI})$ was measured in waters equilibrated with OPC/GGBS (1:9) and OPC/PFA (1:3) cements. The cements were prepared by mixing appropriate amounts of cement powder and tap water to provide pastes with liquid:solid ratios of 0.31 and 0.37 for the OPC/GGBS and OPC/PFA, respectively (Angus et al., 2010). For the pre-addition experiments, the water mixed with the cement powder was amended with $0.5 \% \mathrm{w} / \mathrm{w}$ of the SP or an adjunct. The resulting pastes were poured (50 or $100 \mathrm{~g}$ ) into plastic containers and left to set overnight. The blocks were then de-moulded and cured submerged in tap water for at least $28 \mathrm{~d}$ in sealed containers. During the curing period, the solid: liquid ratio was $2 \mathrm{~kg} / 3 \mathrm{dm}^{3}$, which corresponds to a surface: liquid ratio of $770 \mathrm{~cm}^{2} / \mathrm{dm}^{3}$. Cement-equilibrated solutions were then obtained by filtering the curing water under gravity with qualitative paper (Fisher Scientific) in a nitrogen $\left(\mathrm{N}_{2}\right)$-atmosphere glove-box. The main constituents are shown in Table 1 .

Solubility limits were assessed individually for each radionuclide from the over-saturation direction: $10 \mathrm{~cm}^{3}$ of each type of equilibrated water (OPC/GGBS or OPC/PFA) was added to $15 \mathrm{~cm}^{3}$ plastic tubes and spiked with one of the four isotopes of interest. In the case of $\mathrm{Ni}(\mathrm{II})$, a $100 \mu \mathrm{l}$ aliquot containing $100 \mathrm{kBq}{ }^{63} \mathrm{Ni}$ was added to each tube with sufficient inactive nickel chloride to generate a solution of $10^{-3} \mathrm{M} \mathrm{Ni}$. For $\mathrm{U}(\mathrm{VI})$, the solutions were spiked with a $100 \mu \mathrm{l}$ aliquot containing sufficient uranyl nitrate to generate a solution of $10^{-3} \mathrm{M} \mathrm{U}$. Similarly, a $100 \mu \mathrm{l}$ aliquot containing a $15 \mathrm{kBq}\left(2 \cdot 7 \times 10^{-4} \mathrm{M}\right)$ spike of ${ }^{239} \mathrm{Pu}$ was added for $\mathrm{Pu}(\mathrm{IV})$ and a $250 \mu \mathrm{l}$ aliquot containing a $5 \mathrm{kBq}\left(6 \cdot 6 \times 10^{-7} \mathrm{M}\right)$ spike of ${ }^{241} \mathrm{Am}$ was added for Am(III). Radioactive spikes of ${ }^{63} \mathrm{Ni}$ were added to the solubility experiments as nitrate, ${ }^{239} \mathrm{Pu}$ and ${ }^{241} \mathrm{Am}$ were added as chlorides.

All experiments were carried out in quadruplicate for each radionuclide and aqueous medium. Preparation and sampling were undertaken in a nitrogen-atmosphere glove-box to avoid carbonation and to prevent any changes in the oxidation state of the radionuclides for the duration of the experiments. Based on thermodynamic calculations of the speciation (Pourbaix diagrams) of $\mathrm{U}$ and $\mathrm{Pu}$ under variable $\mathrm{pH}$ and $E_{\mathrm{h}}$ (Salah and Wang, 2014), it was assumed that, under the experimental conditions used here $\left(\mathrm{pH}=12 \cdot 3-12 \cdot 9\right.$ and $E_{\mathrm{h}}$ from +94 to $+292 \mathrm{mV}$, against standard hydrogen electrode (SHE)), there would be no changes to the oxidation state of either $\mathrm{Pu}(\mathrm{IV})$ or U(VI). In the case of the post-addition experiments, SPs (or an adjunct) were added to the cement-equilibrated water samples already spiked with radionuclides, resulting in a final concentration of $0.5 \% \mathrm{w} / \mathrm{w}$. In comparison, the pre-addition samples, which were obtained by equilibration of SP-containing cement blocks in water, contained lower concentrations of the organics in solution $\left(1.5 \times 10^{-4}-1.3 \times 10^{-3} \% \mathrm{w} / \mathrm{w}\right)$, as determined by total organic carbon (TOC) measurement (Sievers InnovOx, GE).

The supernate from each tube was sampled regularly over a period of 2-3 months and the samples filtered before analysis to ensure removal of colloidal particles. In preliminary experiments, filtration of the supernatant solution was attempted with $30 \mathrm{kDa}$ MWCO regenerated cellulose membranes (Millipore Amicon Bioseparations), pre-conditioned with $0 \cdot 1 \mathrm{M}$ sodium hydroxide $(\mathrm{NaOH})$ (laboratory reagent grade, 


\begin{tabular}{|c|c|c|c|c|c|c|c|c|c|c|c|c|c|c|c|c|c|c|}
\hline \multirow[b]{2}{*}{ Sample } & \multicolumn{14}{|c|}{ Concentration: M } & \multirow[b]{2}{*}{$\mathrm{pH}$} & \multirow[b]{2}{*}{$E_{\mathrm{h}}: m V^{\mathrm{a}}$} & \multirow[b]{2}{*}{ TIC: ppm } & \multirow[b]{2}{*}{ TOC: ppm } \\
\hline & Al & $\mathrm{Ca}$ & $\mathrm{k}$ & $\mathrm{Mg}$ & $\mathrm{Na}$ & $\mathrm{Ni}$ & s & $\mathrm{Si}$ & $u$ & $\mathrm{~F}^{-}$ & $\mathrm{Cl}^{-}$ & $\mathrm{Br}^{-}$ & $\mathrm{NO}_{3}{ }^{-}$ & $\mathrm{PO}_{4}^{3-}$ & & & & \\
\hline OPC/PFA & $\left(\times 10^{-4}\right)$ & $\left(\times 10^{-3}\right)$ & $\left(\times 10^{-3}\right)$ & $\left(\times 10^{-4}\right)$ & $\left(\times 10^{-3}\right)$ & $\left(\times 10^{-6}\right)$ & $\left(\times 10^{-5}\right)$ & $\left(\times 10^{-5}\right)$ & $\left(\times 10^{-6}\right)$ & $\left(\times 10^{-4}\right)$ & $\left(\times 10^{-4}\right)$ & $\left(\times 10^{-5}\right)$ & $\left(\times 10^{-5}\right)$ & $\left(\times 10^{-5}\right)$ & - & - & - & - \\
\hline COM1 & $1 \cdot 90 \pm 0 \cdot 10$ & $2 \cdot 10 \pm 0 \cdot 13$ & $2 \cdot 30 \pm 0 \cdot 12$ & $5 \cdot 50 \pm 0 \cdot 28$ & $2 \cdot 50 \pm 0 \cdot 14$ & $1.50 \pm 0.01$ & $3 \cdot 00 \pm 0 \cdot 15$ & $6 \cdot 50 \pm 0.05$ & $1.50 \pm 0.02$ & $2.55 \pm 0.01$ & $7.00 \pm 0.05$ & $1.90 \pm 0.01$ & $6.50 \pm 0.05$ & $5 \cdot 20 \pm 0.02$ & $12 \cdot 3$ & +292 & $2 \cdot 2 \pm 0 \cdot 1$ & $8 \cdot 5 \pm 1 \cdot 0$ \\
\hline COM3 & $1 \cdot 90 \pm 0 \cdot 10$ & $2.00 \pm 0.12$ & $2 \cdot 40 \pm 0 \cdot 12$ & $1.40 \pm 0.07$ & $2 \cdot 70 \pm 0 \cdot 14$ & $1.80 \pm 0.01$ & $3 \cdot 00 \pm 0 \cdot 15$ & $6.50 \pm 0.05$ & $1.80 \pm 0.02$ & $2.55 \pm 0.01$ & $7.00 \pm 0.05$ & $1.90 \pm 0.01$ & $6.50 \pm 0.05$ & $5 \cdot 20 \pm 0.02$ & $12 \cdot 3$ & $\begin{array}{l}+292 \\
\end{array}$ & $2 \cdot 9 \pm 0 \cdot 1$ & $5 \cdot 2 \pm 0.5$ \\
\hline COM4 & $1 \cdot 90 \pm 0 \cdot 10$ & $1.30 \pm 0.08$ & $2 \cdot 50 \pm 0.12$ & $1.20 \pm 0.06$ & $2 \cdot 70 \pm 0 \cdot 14$ & $1.50 \pm 0.01$ & $3.00 \pm 0.15$ & $6 \cdot 50 \pm 0.05$ & $1.50 \pm 0.02$ & $2.55 \pm 0.01$ & $7.00 \pm 0.05$ & $1.90 \pm 0.01$ & $6.50 \pm 0.05$ & & $12 \cdot 3$ & +292 & & $6 \cdot 2 \pm 0.5$ \\
\hline $\mathrm{BIO}$ & $1 \cdot 90 \pm 0 \cdot 10$ & $0.58 \pm 0.03$ & $1.80 \pm 0.09$ & $0.93 \pm 0.05$ & $1 \cdot 90 \pm 0 \cdot 10$ & $1.60 \pm 0.01$ & $3 \cdot 00 \pm 0 \cdot 15$ & $6.50 \pm 0.05$ & $1.60 \pm 0.02$ & $2.55 \pm 0.01$ & $7.00 \pm 0.05$ & $1.90 \pm 0.01$ & $6.50 \pm 0.05$ & $5 \cdot 20 \pm 0.02$ & $12 \cdot 3$ & +292 & $1 \cdot 3 \pm 0 \cdot 1$ & $0.7 \pm 0.1$ \\
\hline VMA & $1.90 \pm 0.10$ & $1 \cdot 10 \pm 0.07$ & $2 \cdot 10 \pm 0 \cdot 10$ & $1 \cdot 10 \pm 0.06$ & $2 \cdot 20 \pm 0 \cdot 12$ & $1.70 \pm 0.01$ & $3.00 \pm 0.15$ & $6.50 \pm 0.05$ & $1 \cdot 70 \pm 0.02$ & $2.55 \pm 0.01$ & $7.00 \pm 0.05$ & $1.90 \pm 0.01$ & $6.50 \pm 0.05$ & $5 \cdot 20 \pm 0.02$ & $12 \cdot 3$ & +292 & $1 \cdot 5 \pm 0 \cdot 1$ & $8 \cdot 9 \pm 1 \cdot 0$ \\
\hline DEF & $1 \cdot 90 \pm 0 \cdot 10$ & $1 \cdot 30 \pm 0.08$ & $1 \cdot 90 \pm 0 \cdot 10$ & $0.86 \pm 0.04$ & $2 \cdot 10 \pm 0 \cdot 12$ & $1.50 \pm 0.01$ & $3 \cdot 00 \pm 0 \cdot 15$ & $6.50 \pm 0.05$ & $1 \cdot 50 \pm 0.02$ & $2.55 \pm 0.01$ & $7.00 \pm 0.05$ & $1.90 \pm 0.01$ & $6.50 \pm 0.05$ & $5 \cdot 20 \pm 0.02$ & $12 \cdot 3$ & +292 & $1 \cdot 6 \pm 0 \cdot 1$ & $1 \cdot 4 \pm 0.1$ \\
\hline BSP1 & $1 \cdot 90 \pm 0 \cdot 10$ & $1.20 \pm 0.07$ & $2 \cdot 10 \pm 0 \cdot 10$ & $1.20 \pm 0.06$ & $2 \cdot 40 \pm 0 \cdot 13$ & $1 \cdot 70 \pm 0.01$ & $3 \cdot 00 \pm 0 \cdot 15$ & $6 \cdot 50 \pm 0.05$ & $1 \cdot 70 \pm 0.02$ & $2.55 \pm 0.01$ & & & $6.50 \pm$ & & $12 \cdot 3$ & +292 & $1 \cdot 7 \pm 0 \cdot 1$ & $1 \cdot 2 \pm 0.1$ \\
\hline $\begin{array}{l}\text { OPC/GGBS } \\
\text { COM1 }\end{array}$ & $\begin{array}{r}\left(\times 10^{-4}\right) \\
2.80 \pm 0.14\end{array}$ & $8 \cdot 10 \pm 0 \cdot 49$ & $7 \cdot 00 \pm 0.35$ & $6.40 \pm 0.32$ & $7 \cdot 50 \pm 0.41$ & $1.70 \pm 0.01$ & $3.00 \pm 0.15$ & $3.20 \pm 0.05$ & $1.70 \pm 0.02$ & $2.55 \pm 0.01$ & $6.20 \pm 0.03$ & $1.90 \pm 0.01$ & $1 \cdot 40 \pm 0.01$ & $5 \cdot 20 \pm 0.02$ & $12 \cdot 9$ & +94 & $1 \cdot 1 \pm 0 \cdot 1$ & $2 \cdot 7 \pm 0.1$ \\
\hline COM2 & $2 \cdot 80 \pm 0.14$ & $7 \cdot 20 \pm 0 \cdot 43$ & $8.00 \pm 0.40$ & $6 \cdot 00 \pm 0 \cdot 30$ & $8.60 \pm 0.50$ & $1.60 \pm 0.01$ & $3 \cdot 00 \pm 0 \cdot 15$ & $3.20 \pm 0.05$ & $1.60 \pm 0.02$ & $2.55 \pm 0.01$ & $6 \cdot 20 \pm 0 \cdot 03$ & $1.90 \pm 0.01$ & $1.40 \pm 0.01$ & 5.20 & 10 & $\begin{array}{r}+94 \\
+94\end{array}$ & $1 \cdot 4 \pm 0 \cdot 1$ & $0.40 \pm 0.05$ \\
\hline сOM3 & $2 \cdot 80 \pm 0.14$ & $6 \cdot 10 \pm 0.37$ & $8.60 \pm 0.43$ & $5 \cdot 80 \pm 0.30$ & $9.60 \pm 0.53$ & $1.60 \pm 0.01$ & $3.00 \pm 0.15$ & $3.20 \pm 0.05$ & $1.60 \pm 0.02$ & $2.55 \pm 0.01$ & $6.20 \pm 0.03$ & $1.90 \pm 0.01$ & $1 \cdot 40 \pm 0.01$ & $5 \cdot 20 \pm 0.02$ & $12 \cdot 8$ & +94 & $0.8 \pm 0.1$ & $2 \cdot 1 \pm 0.1$ \\
\hline COM4 & $2 \cdot 80 \pm 0 \cdot 14$ & $5 \cdot 30 \pm 0.32$ & $6.30 \pm 0.32$ & $10 \cdot 0 \pm 0 \cdot 4$ & $8.10 \pm 0.45$ & $1.80 \pm 0.01$ & $3.00 \pm 0.15$ & $3.20 \pm 0.05$ & $1.80 \pm 0.02$ & $2.55 \pm 0.01$ & $6.20 \pm 0.03$ & $1.90 \pm 0.01$ & $1 \cdot 40 \pm 0.01$ & $5 \cdot 20 \pm 0.02$ & $12 \cdot 8$ & +94 & $1 \cdot 0 \pm 0 \cdot 1$ & $1 \cdot 0 \pm 0.1$ \\
\hline $\mathrm{BIO}$ & $2 \cdot 80 \pm 0.14$ & $4.90 \pm 0.29$ & $9 \cdot 10 \pm 0.46$ & $5 \cdot 60 \pm 0.28$ & $9.50 \pm 0.52$ & $1.70 \pm 0.01$ & $3.00 \pm 0.15$ & $3.20 \pm 0.05$ & $1.70 \pm 0.02$ & $2.55 \pm 0.01$ & $6.20 \pm 0.03$ & $1.90 \pm 0.01$ & $1 \cdot 40 \pm 0.01$ & $5 \cdot 20 \pm 0.02$ & $12 \cdot 9$ & +94 & $1 \cdot 3 \pm 0 \cdot 1$ & $1.8 \pm 0.1$ \\
\hline VMA & $2 \cdot 80 \pm 0 \cdot 14$ & $4 \cdot 40 \pm 0 \cdot 16$ & $6 \cdot 60 \pm 0.33$ & $4 \cdot 90 \pm 0 \cdot 20$ & $6 \cdot 40 \pm 0 \cdot 35$ & $1.80 \pm 0.01$ & $3 \cdot 00 \pm 0 \cdot 15$ & $3.20 \pm 0.05$ & $1.80 \pm 0.02$ & $2.55 \pm 0.01$ & $6 \cdot 20 \pm 0.03$ & $1.90 \pm 0.01$ & $1.40 \pm 0.01$ & & $12 \cdot 8$ & $\begin{array}{r}+94 \\
\end{array}$ & $1 \cdot 4 \pm 0 \cdot 1$ & $1 \cdot 6 \pm 0.1$ \\
\hline DEF & $2 \cdot 80 \pm 0 \cdot 14$ & $3 \cdot 40 \pm 0 \cdot 20$ & $9.90 \pm 0.50$ & $4 \cdot 10 \pm 0 \cdot 20$ & $9.40 \pm 0.51$ & $1.60 \pm 0.01$ & $3 \cdot 00 \pm 0 \cdot 15$ & $3.20 \pm 0.05$ & $1.60 \pm 0.02$ & $2.55 \pm 0.01$ & $6 \cdot 20 \pm 0.03$ & $1.90 \pm 0.01$ & $1.40 \pm 0.01$ & $5.20 \pm 0.02$ & $12 \cdot 9$ & +94 & $0.8 \pm 0.1$ & $0.8 \pm 0.1$ \\
\hline BSP1 & $2 \cdot 80 \pm 0 \cdot 14$ & $4 \cdot 30 \pm 0 \cdot 26$ & $7 \cdot 80 \pm 0.39$ & $3 \cdot 10 \pm 0 \cdot 16$ & $7 \cdot 40 \pm 0 \cdot 40$ & $1.60 \pm 0.01$ & $3 \cdot 00 \pm 0 \cdot 15$ & $3.20 \pm 0.05$ & $1.60 \pm 0.02$ & $2.55 \pm 0.01$ & $6 \cdot 20 \pm 0.03$ & $1.90 \pm 0.01$ & 0.01 & 02 & 12.9 & +94 & $1 \cdot 1 \pm 0 \cdot 1$ & $0.8 \pm 0.1$ \\
\hline Blank & $2.79 \pm 0.14$ & $5 \cdot 60 \pm 0 \cdot 44$ & $9 \cdot 60 \pm 0.48$ & $5.90 \pm 0.29$ & $10 \cdot 0 \pm 1 \cdot 0$ & $1.80 \pm 0.01$ & $3 \cdot 11 \pm 0 \cdot 15$ & $3.16 \pm 0.05$ & $1.80 \pm 0.02$ & $2.55 \pm 0.01$ & $6 \cdot 20 \pm 0.03$ & $1.90 \pm 0.01$ & $1 \cdot 40 \pm 0.01$ & $5.20 \pm 0.02$ & $12 \cdot 8$ & +94 & $0.9 \pm 0.1$ & $0.10 \pm 0.05$ \\
\hline
\end{tabular}

Note: The data correspond to the mean $\pm S D(n=3)$. BIO, biocide; DEF, de-foaming agent; $\mathrm{TIC}$, total inorganic carbon, expressed as ppm of $\mathrm{C} ; \mathrm{TOC}$, total organic carbon; VMA, viscosity modifying agent

${ }^{\mathrm{a}} E_{\mathrm{h}}$ values against standard hydrogen reference electrode (SHE)

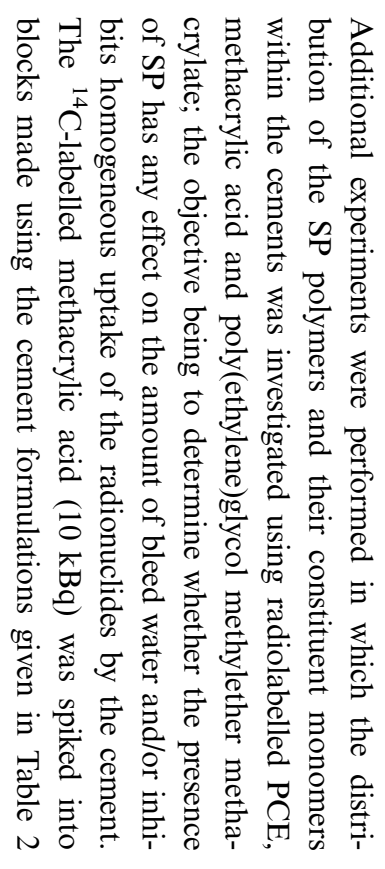

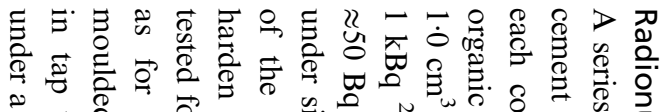
要.

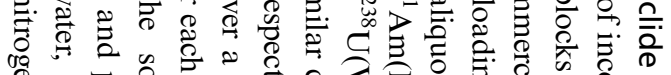

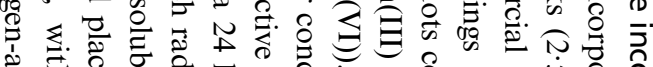

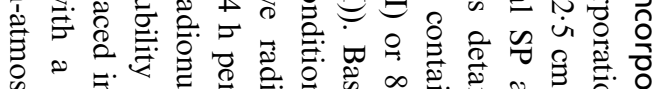

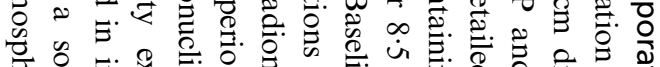

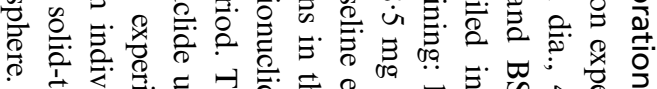

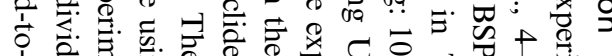

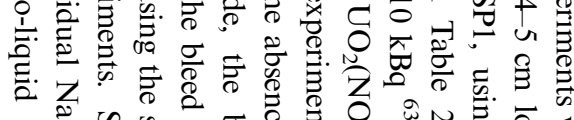

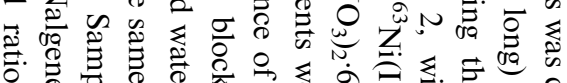

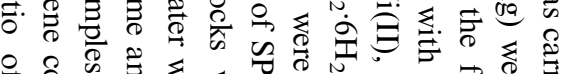

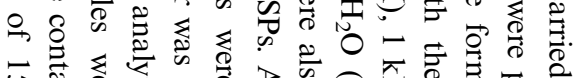

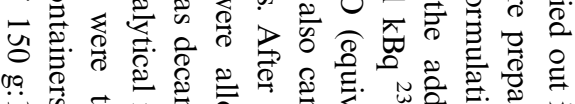

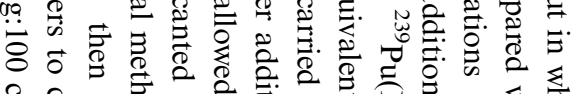

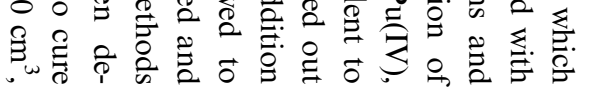

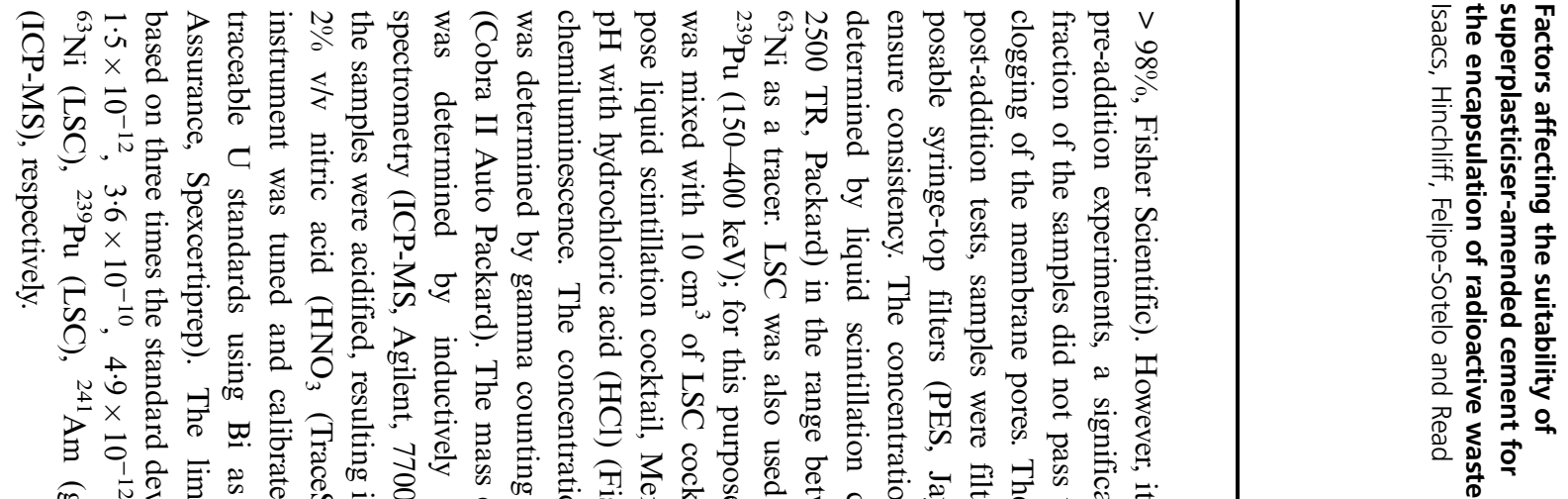


Table 2. Composition of blended cements used for the bleed tests

\begin{tabular}{lccccc} 
Cement & GGBS (equivalents) & PFA (equivalents) & OPC (equivalents) & SP \% by weight of cement & Water content (w/w) \\
\hline OPC/GGBS & 9 & 0 & 1 & 0.5 & 0.31 \\
OPC/PFA & 0 & 3 & 1 & 0.5 & 0.37 \\
OPC/GGBS blank & 9 & 0 & 1 & 0 & 0.31 \\
OPC/PFA blank & 0 & 3 & 1 & 0 & 0.37
\end{tabular}

and allowed to cure for $28 \mathrm{~d}$ before autoradiography. The ${ }^{14} \mathrm{C}$-labelled BSP1 was made by way of a scaled down version (by a factor of six) of the reaction in Figure S2; a spike containing $200 \mathrm{kBq}{ }^{14} \mathrm{C}$-labelled methacrylic acid was added and the reaction was left to proceed as normal. ${ }^{14} \mathrm{C}$-labelled PEGMA was produced from ${ }^{14} \mathrm{C}$-labelled PEG and methacryloyl chloride based on the synthesis described by Li and Kao (2003). The ${ }^{14} \mathrm{C}$-labelled BSP1 was purified by dialysis to remove unreacted materials following the same procedure as for the isotopically stable BSP1. A $10 \mathrm{kBq}$ spike was added to the cement blocks and the blocks were cured, as above.

The curing or equilibration period ranged from $28 \mathrm{~d}$ for the experiments with ${ }^{14} \mathrm{C}$-labelled SP to 1 year for the tests on radionuclide retardation. The distribution of the radionuclides and the ${ }^{14} \mathrm{C}$-labelled organics in the hardened cement samples was determined by digital autoradiography. The blocks were removed from the curing water and cut axially using a diamond-edged circular saw. They were placed cut side down onto $\mathrm{Eu}^{2+}$-doped barium fluorobromide (BaFBr) storage phosphor autoradiographic plates (Fuji BAS MP 2025, $20 \mathrm{~cm} \times 25 \mathrm{~cm}$ ) and exposed from 5 to $21 \mathrm{~d}$ depending on the activity of the sample. The plates were developed using a scanning laser beam (Auto RAD, Packard Cyclone) and the images processed using ImageQuant (version 4) and ImageJ (U.S. National Institute of Health).

\section{Results}

\section{Solubility studies}

The baseline solubility of $\mathrm{Ni}$ in the OPC/PFA-equilibrated water was $1.0 \times 10^{-7} \pm 1 \cdot 8 \times 10^{-8} \mathrm{M}$. The commercial SPs have a significant effect on the $\mathrm{Ni}$ concentration in solution but only in the post-addition experiments (Figure 1(a)), where the added concentration of $\mathrm{SP}$ is $0.5 \% \mathrm{w} / \mathrm{w}$, and $\mathrm{Ni}$ concentrations increase by two orders of magnitude to more than $10^{-5} \mathrm{M}$. The results are very similar for all four commercial SP products. Increased $\mathrm{Ni}$ solubility is also observed in the case of the OPC/GGBS-equilibrated water (Figure 1(c)). In this case, the baseline solubility is slightly higher, $3.2 \times 10^{-7} \pm 1 \cdot 7 \times 10^{-8} \mathrm{M}$, which could be due to the higher $\mathrm{pH}$ of the solution (Table 1). In comparison, the purified BSP1 has little impact on Ni solubility beyond $35 \mathrm{~d}$ (Figures 1(b) and 1(d)). None of the adjuncts, when tested in isolation, affects Ni solubility in either of the cement-equilibrated waters, whether the experiments are conducted under pre- or postaddition conditions.
The commercial SPs also increase the solubility of U(VI), by approximately one order of magnitude in the OPC/PFAequilibrated waters (Figures 2(a) and 2(c)). The corresponding increase with BSP1 is much smaller and may not be significant when analytical errors are considered (Figures 2(b) and 2(d)). As in the case of $\mathrm{Ni}$, the adjuncts have no effect on the solubility of U(VI) in either of the two cement-equilibrated waters.

The baseline solubility of $\mathrm{Pu}(\mathrm{IV})$ in the OPC/PFA-equilibrated water is $4.2 \times 10^{-10} \pm 4 \cdot 1 \times 10^{-11} \mathrm{M}$, one order of magnitude lower than the concentration in OPC/GGBS, $1.9 \times 10^{-9} \pm 1.7 \times 10^{-9} \mathrm{M}$. Whereas the adjuncts have no effect on the solubility of $\mathrm{Pu}(\mathrm{IV})$ in either cement solution, the commercial SPs cause a significant increase in $\mathrm{Pu}$ solubility, of between two and three orders of magnitude. Post-addition of COM1 increases the solubility of $\mathrm{Pu}(\mathrm{IV})$ to $8 \cdot 8 \times 10^{-7} \pm 7 \cdot 1 \times 10^{-7}$ and $8.4 \times 10^{-7} \pm 9 \cdot 9 \times 10^{-7} \mathrm{M}$ for OPC/PFA and OPC/GGBS, respectively (Figures 3(a) and 3(c)), although there is considerable variability for the latter system. The purified BSP1 also appears to cause an increase in $\mathrm{Pu}$ solubility, but only in the OPC/PFA water; the results for OPC/GGBS overlapping the baseline concentrations. However, the increase is not as pronounced as for the commercial products, the presence of BSP1 resulting in a $\mathrm{Pu}$ concentration of $1 \cdot 6 \times 10^{-7} \pm 8 \cdot 8 \times 10^{-8} \mathrm{M}$, compared to $8 \cdot 8 \times 10^{-7} \pm 7 \cdot 1 \times$ $10^{-7} \mathrm{M}$ with the same concentration of COM1.

Solubility data for americium are only available for the commercial SP (see Figure 4). The baseline concentration of $\mathrm{Am}(\mathrm{III})$ in the OPC/PFA solution is $7 \cdot 3 \times 10^{-11} \pm$ $4.2 \times 10^{-11} \mathrm{M}$, similar to the value obtained in OPC/GGBS, $8.4 \times 10^{-11} \pm 4.4 \times 10^{-11} \mathrm{M}$. As for the other radionuclides, the behaviour of Am(III) with the four commercial products, COM1-COM4, is very similar. Under post-addition conditions $(0.5 \% \mathrm{w} / \mathrm{w})$, they cause an increase in Am solubility to $2.5 \times 10^{-8} \pm 5.3 \times 10^{-9}$ and $3.4 \times 10^{-7} \pm 3 \cdot 8 \times 10^{-7} \mathrm{M}$ for OPC/PFA and OPC/GGBS-equilibrated solutions, respectively. However, the smaller quantities present under pre-addition conditions (approximately $0 \cdot 03-0 \cdot 3 \%$ of the original load) have little or no impact.

\section{Radionuclide incorporation}

Experiments were carried out in which the SPs (COM1COM4 and BSP1, at a concentration of $0.5 \% \mathrm{w} / \mathrm{w}$ ) were mixed with OPC/PFA or OPC/GGBS grout, with and without radionuclides present. During the first $24 \mathrm{~h}$ of setting any bleed 


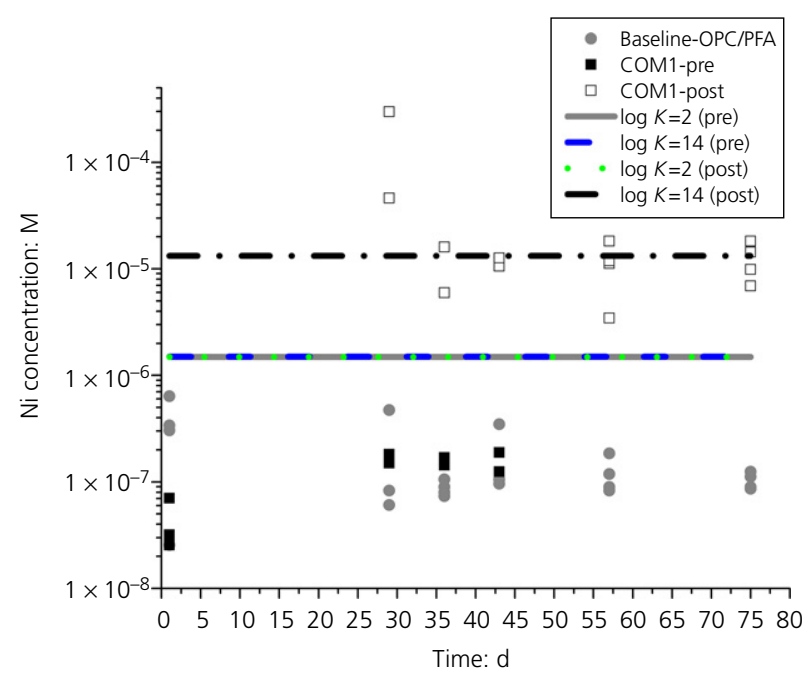

(a)

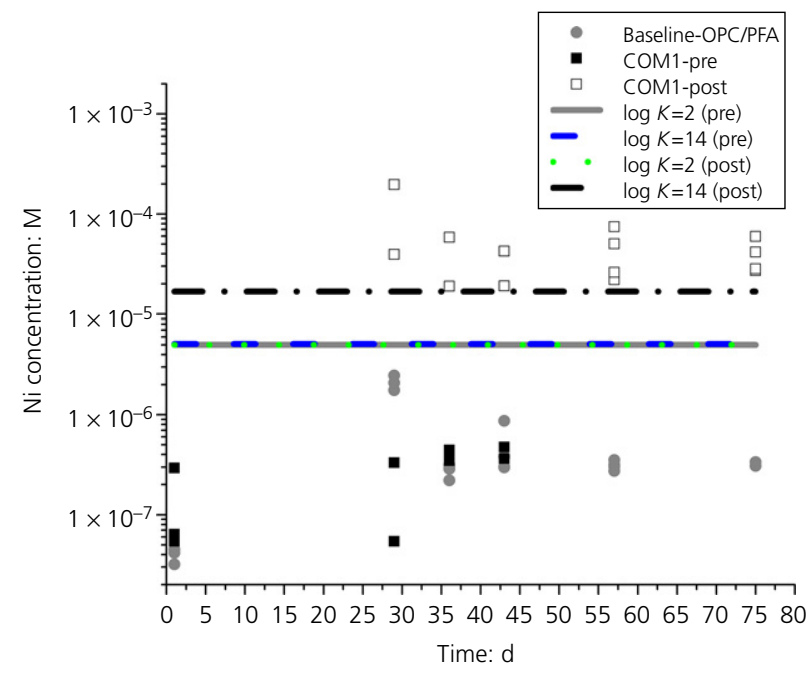

(c)

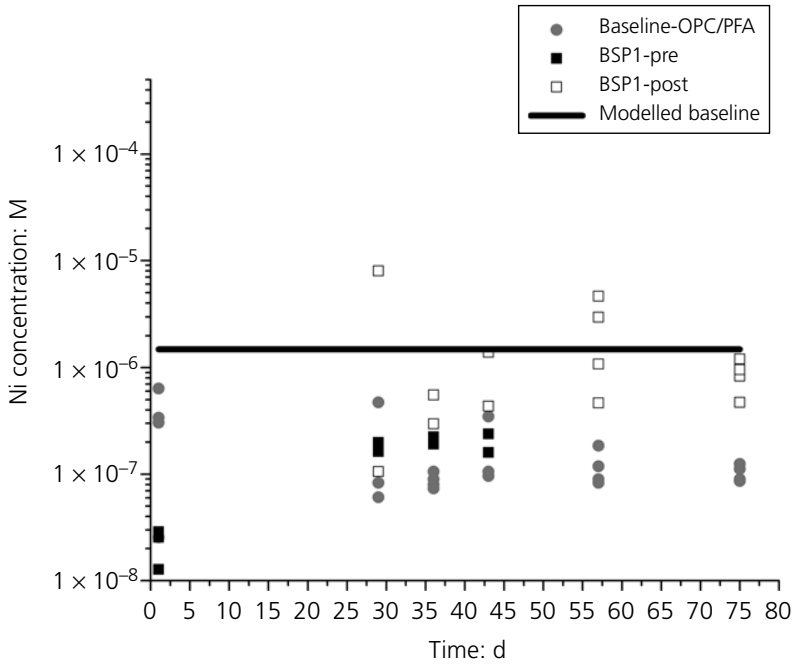

(b)

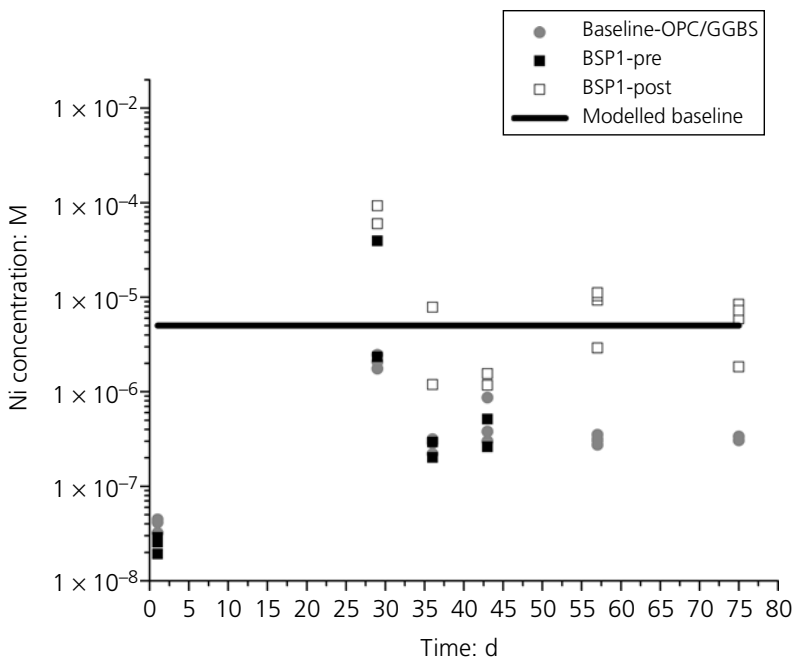

(d)

Figure 1. Experimental and modelling results showing the solubility of $\mathrm{Ni}(I)$ in: (a) OPC/PFA equilibrated water in the presence of COM1; (b) OPC/PFA equilibrated water in the presence of BSP1; (c) OPC/GGBS equilibrated water in the presence of COM1; (d) OPC/GGBS equilibrated water in the presence of BSP1

water accumulating on top of the grout was collected for analysis. Obvious differences between the grouts were immediately apparent. In the absence of SP, no bleed was observed regardless of the grout composition. However, addition of the commercial SP causes a very marked increase in the amount of bleed water in the case of OPC/GGBS, up to $10 \%$ of the mass of the block (approximately $30 \%$ of the original volume of water in the mixture) at the dosages shown in Table 2. The corresponding value for BSP1 was $3 \%$ of the weight of the OPC/GGBS block or $9 \%$ of the water added. The results of tests on OPC/PFA with the SP were less reproducible, ranging from $0 \cdot 5$ to $3 \%$ of the weight of the blocks.

Figure 5 shows the quantity of each radionuclide present in the bleed water as a percentage of the inventory added to the grouts; the amount lost to bleed is much higher in the case of the OPC/GGBS grout, reaching $8 \%$ in the case of nickel and COM2. Bleed waters from all of the commercial SP are affected to some extent, with $\mathrm{Ni}$ followed by $\mathrm{Pu}$ displaying the greatest tendency for mobilisation. In contrast, radionuclide activities in the bleed water from the bespoke BSP1 are close to the LOD. Radionuclide activities in the bleed water from the OPC/PFA grout never exceed $0 \cdot 015 \%$ of the original load (Figure 5).

The results described above suggest that commercial SPs at a loading of $0.5 \% \mathrm{w} / \mathrm{w}$ both promote bleed in OPC/GGBS blends and inhibit radionuclide uptake. It is reasonable to assume, therefore, that a relationship exists between bleed and the distribution of radionuclides within the cement matrix. In 


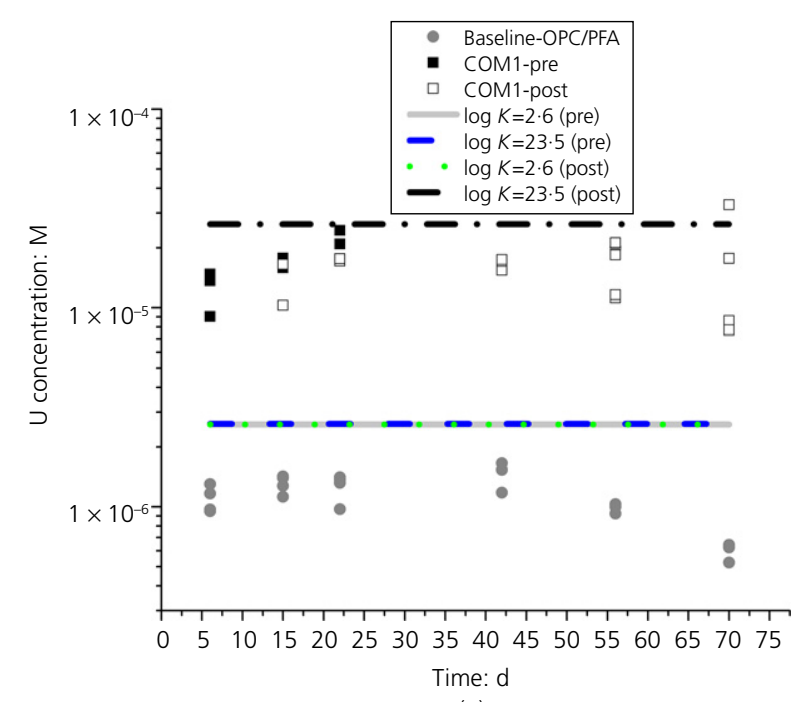

(a)

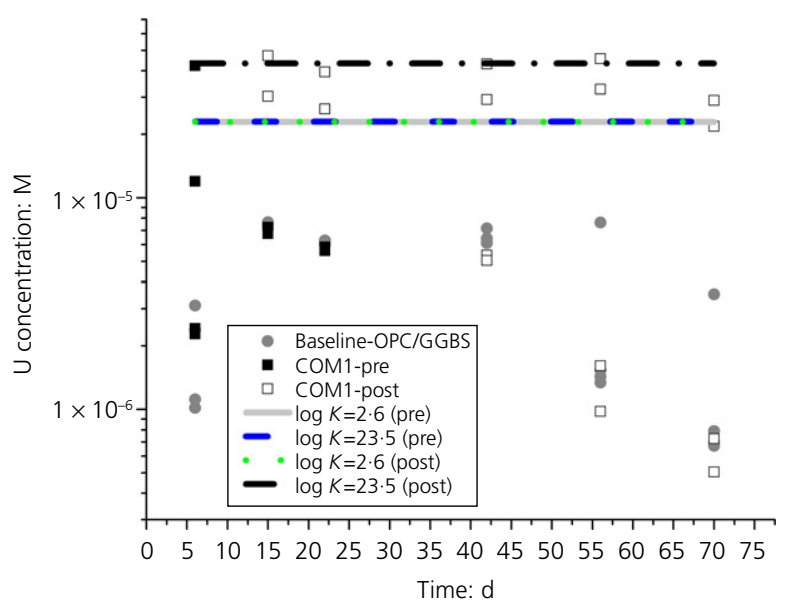

(c)

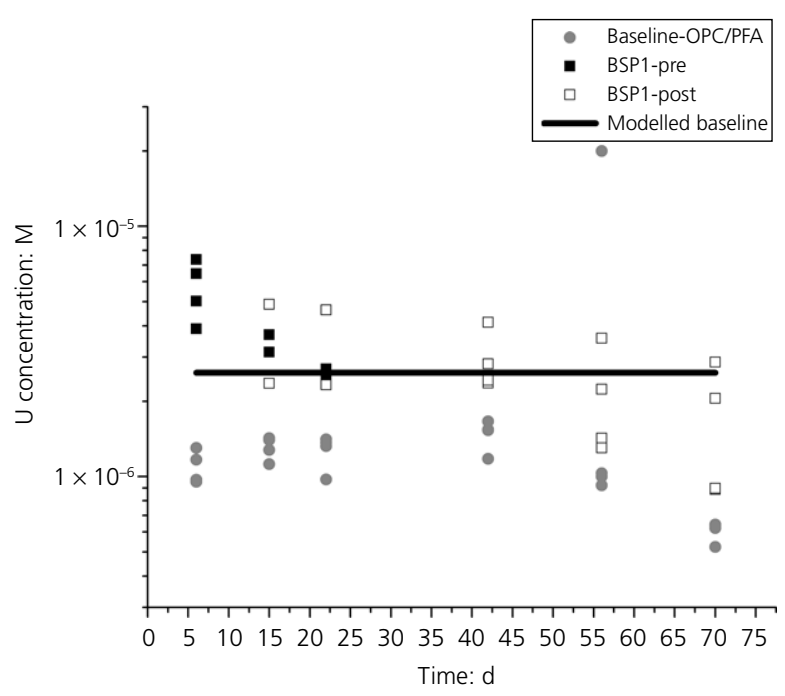

(b)

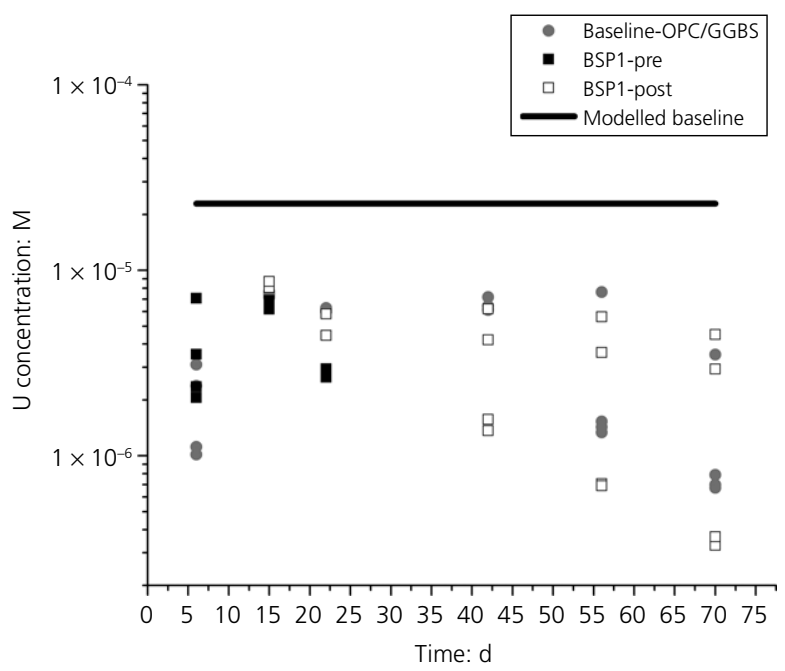

(d)

Figure 2. Experimental and modelling results showing the solubility of $\mathrm{U}(\mathrm{VI})$ in: (a) OPC/PFA equilibrated water in the presence of COM1; (b) OPC/PFA equilibrated water in the presence of BSP1; (c) OPC/GGBS equilibrated water in the presence of COM1; (d) OPC/GGBS equilibrated water in the presence of BSP1

order to gain further understanding of the interaction between the cement particles and the SP, an additional set of experiments was carried out in which BSP1 was labelled with ${ }^{14} \mathrm{C}$ before mixing with the grout. The distribution of the ${ }^{14}$ C-labelled SP was then observed by autoradiographic imaging and compared to the distributions of radionuclides within the cement in the presence of the SP. Figure 6(a) shows that the distribution of ${ }^{14} \mathrm{C}$-labelled BSP1 within the OPC/GGBS block is not homogeneous and a gradient exists, with higher concentrations of SP near the surface. This pattern is mirrored by the distribution of the radionuclides in the cement matrix; U(VI) is shown as an example in Figure 6(b). In the absence of SP, the autoradiography images showed a homogeneous distribution of the radionuclides within the blocks.

\section{Discussion}

\section{Solubility considerations}

Without SP present, the experimentally determined solubility of $\mathrm{Ni}$ (II) in the two cement waters fits well with the results obtained by Pilkington and Stone (1990), within the range $10^{-6}-10^{-8} \mathrm{M}$ for similar cement-equilibrated water compositions ( $\mathrm{pH}$ ranging from 11.8 for $1: 10 \mathrm{OPC} / \mathrm{PFA}$, to 12.5 for 1:3 OPC/GGBS). Thermodynamic calculations using the JChess code (version 3.0 (van der Lee and De Windt, 2002)) and published data (Hatches, version 20, Hatches-Database (2016)) indicate that the dominant species in solution is $\mathrm{Ni}(\mathrm{OH})_{3}{ }^{-}$with the solubility controlling phase predicted to be $\beta$-nickel (II) hydroxide $\left(\beta\right.$ - $\left.\mathrm{Ni}(\mathrm{OH})_{2}\right)$. 


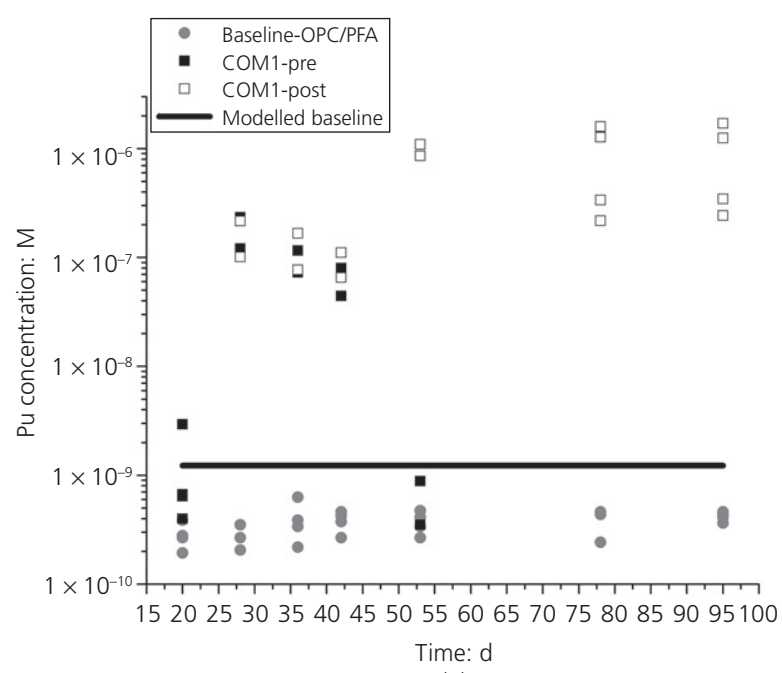

(a)

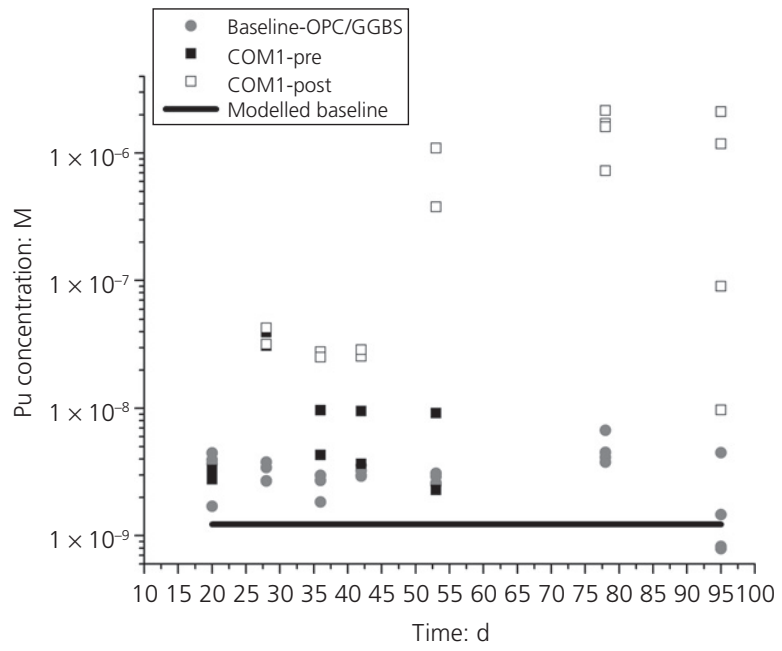

(c)

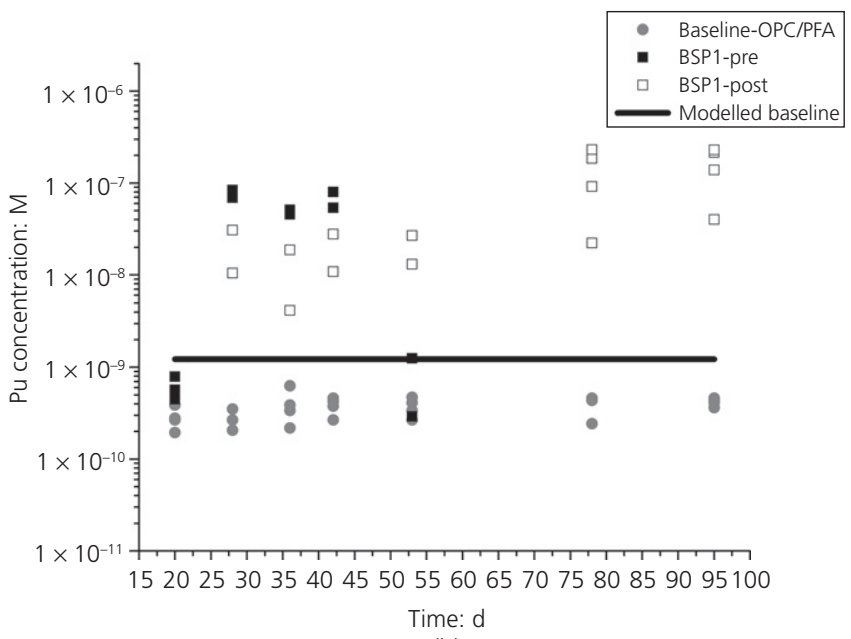

(b)

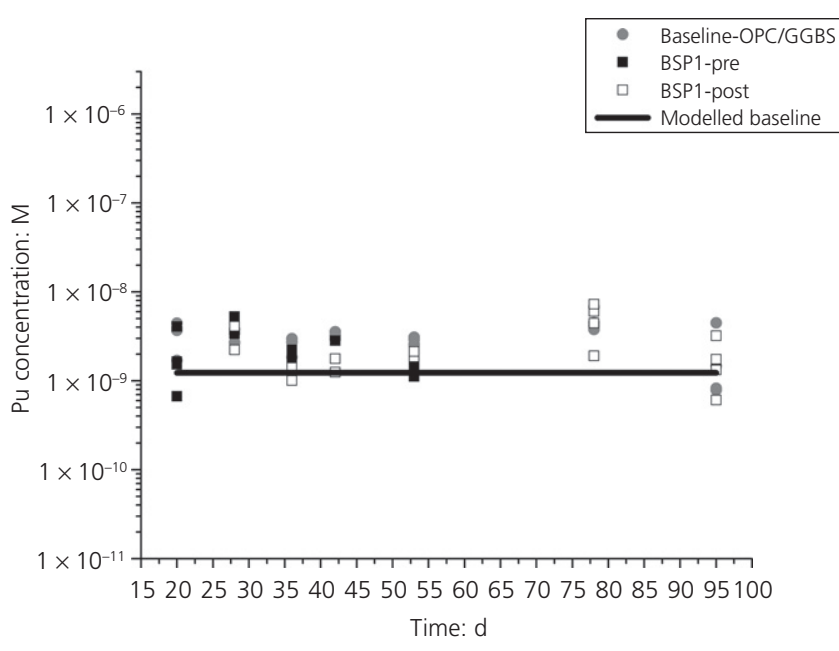

(d)

Figure 3. Experimental and modelling results showing the solubility of Pu(IV) in: (a) OPC/PFA equilibrated water in the presence of COM1; (b) OPC/PFA equilibrated water in the presence of BSP1; (c) OPC/GGBS equilibrated water in the presence of COM1; (d) OPC/GGBS equilibrated water in the presence of BSP1

The enhancement of $\mathrm{Ni}$ solubility observed experimentally is higher than that reported by Young (2012), following the addition of $10 \% \mathrm{w} / \mathrm{v}$ ADVA Cast 551 to a variety of cementequilibrated waters. However, the baseline solubility reported by Young (2012) was much higher than that obtained here $\left(5 \cdot 7 \times 10^{-5}-9.6 \times 10^{-5} \mathrm{M}\right)$, which may reflect differences in filtration or the crystallinity of the solubility controlling phase. Other studies using lower concentrations of the same SP (ADVA Cast 551 at $0.001,0.01$ and $0 \cdot 1 \%$ ) in saturated calcium hydroxide $\left(\mathrm{Ca}(\mathrm{OH})_{2}\right)$ showed solubility enhancement factors from 2.7 to 83 when compared to a baseline solubility of $1 \cdot 4-1 \cdot 5 \times 10^{-7} \mathrm{M}$ (Clacher et al., 2013a).

The differences observed between the behaviour of $\mathrm{Ni}$ in the presence of the commercial SP products and the purified
BSP1, together with the fact that various adjuncts appear to have no effect on Ni solubility, suggest that the species responsible for the increase in solubility could be small fragments of the SP polymer and/or one of the monomers used in SP synthesis, in particular PEGMA. These compounds are known to modify their steric configuration at high $\mathrm{pH}$ (as illustrated in Figure S5), behaving similarly to crown ethers or pseudo-cryptands (Balasubramanian and Chandani, 1983; Chen et al., 2005; Totten et al., 1998), which could increase the observed radionuclide concentration in solution by chelation.

Research carried out by Plank and Hirsch (2007) and Yu et al. (2013) concluded that the mechanism of action of comb-like $\mathrm{SP}$ is by interaction of the negatively charged polymer with the 


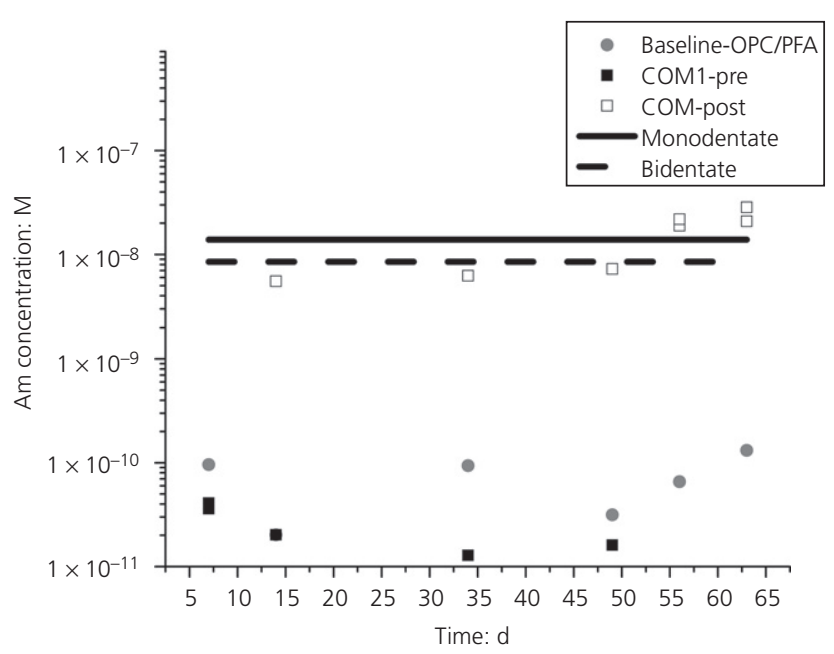

(a)

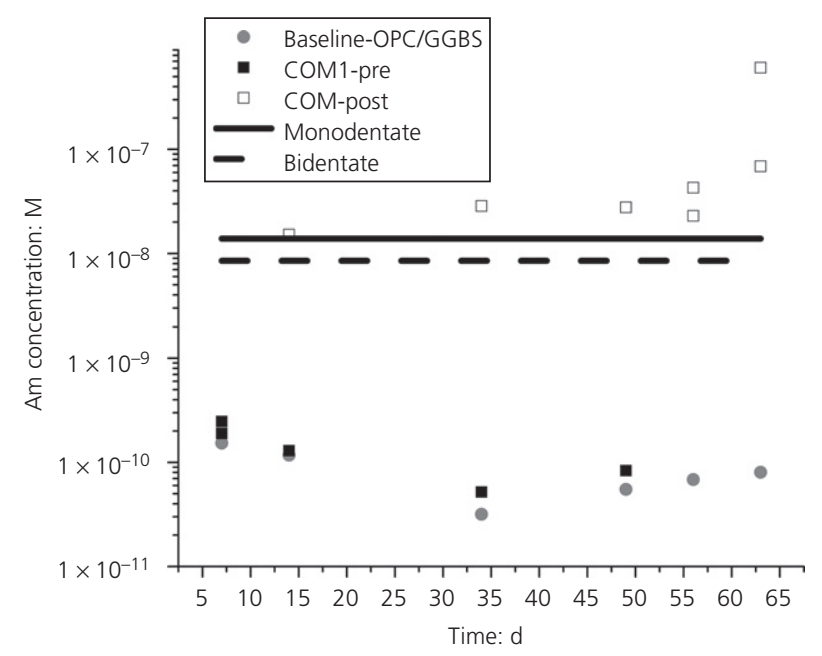

(b)

Figure 4. Experimental and modelling results showing the solubility of Am(III) in the presence of COM1 in: (a) OPC/PFA equilibrated water and (b) OPC/GGBS equilibrated water

surface of the cement particles. Although chelation of $\mathrm{Ca}^{2+}$ ions on the surface of cement minerals seems to be the accepted mechanism for explaining the dispersing effect of the SP, stability constants for the complexation of $\mathrm{Ca}^{2+}$, or other bivalent cations such as $\mathrm{Ni}^{2+}$, with the polycarboxylate $\mathrm{SP}$ or the PEG chains could not be found in the peer-reviewed literature. Therefore, to assess the hypothesis that nickel solubility increases in the presence of comb-type SP as a result of chelation with PEG and, given the chemical similarities between the PEG molecule and crown ethers, stability constants for $\mathrm{Ni}$ complexation with the latter were taken as a starting point for estimating a conditional stability constant for the SP. It should be pointed out that, due to the lack of information regarding the complexation capacity of PCE-type SP and their derivatives/impurities, conditional stability constants have been taken from different sources, some of which may have been

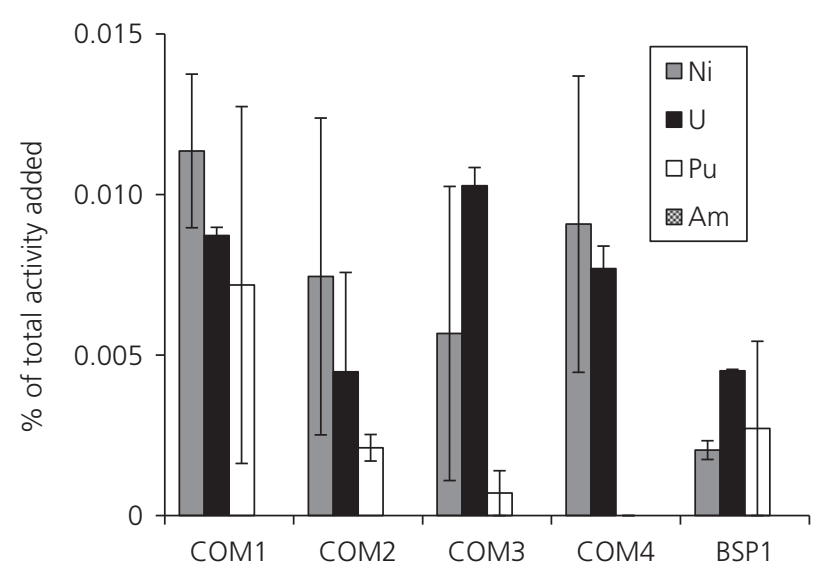

(a)

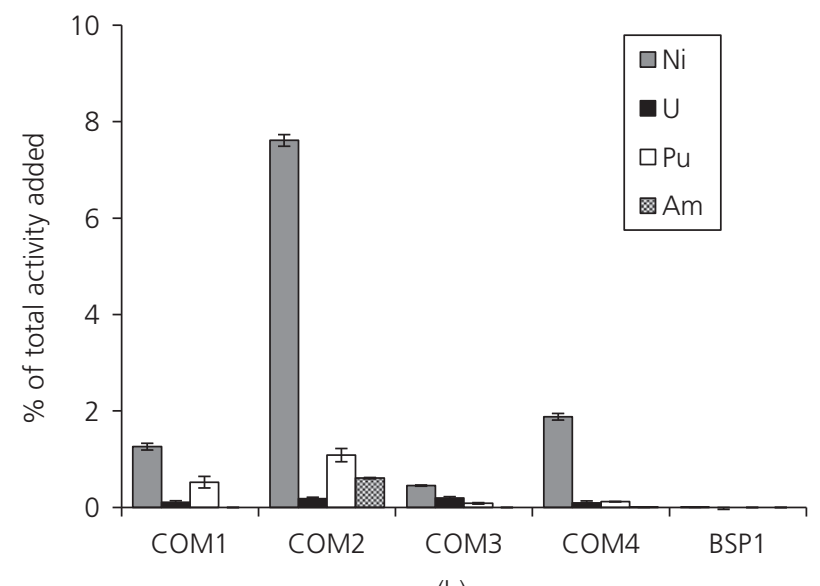

(b)

Figure 5. Percentage of the total radionuclide loading in bleed water for (a) OPC/PFA and (b) OPC/GGBS grouts

determined under different conditions from those used in this work. Therefore, predicted values should be treated with caution and as no more than indicative in order to infer the potential complexation behaviour of PCE-SP. Considering the total organic content (TOC, as ppm of C) in the cement leachates and assuming that all of the SPs in solution behave as 15-crown-5 with $\log K=2$ (Izatt et al., 1976; Sil and Srivastava, 2004) for their complexation with $\mathrm{Ni}$, the predicted concentration of the $\mathrm{Ni}$ complex would still be negligible in all of the systems studied, regardless of the $\mathrm{pH}$ or the concentration of the organics (pre- compared with post-additions), as shown in Figures 1(a) and 1(c). The conditional constant would need to increase to $\log K=14$ before a reasonable correspondence between the experimental and calculated values for the post-addition conditions is obtained. This apparent discrepancy merits further investigation, including consideration of ternary complexes that could modify the speciation (Gaona et al., 2008). Using the same estimated stability constant for the pre-addition conditions, where the concentration of SP is only $10^{-4}-10^{-3} \%$, the contribution of the organic component 


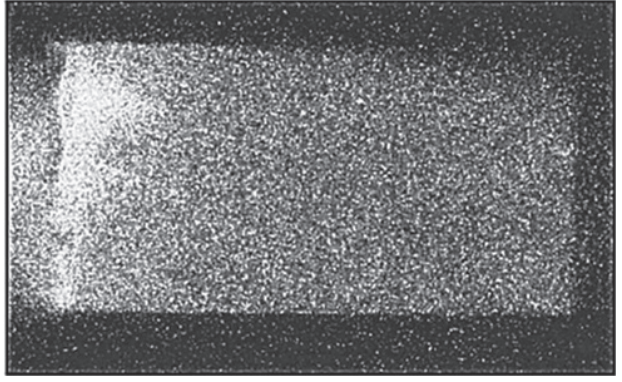

(a)

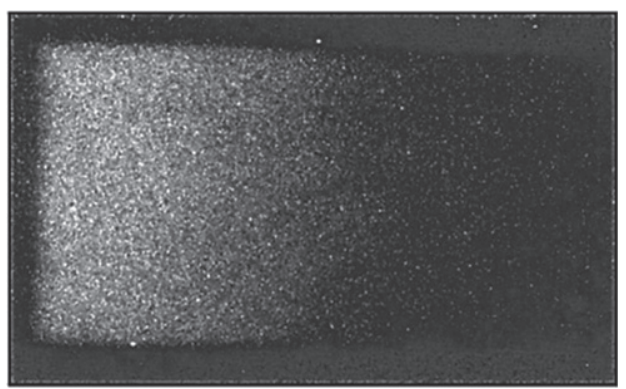

(b)

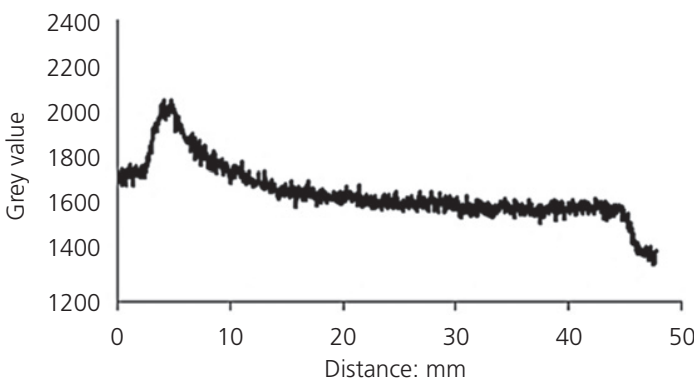

(c)

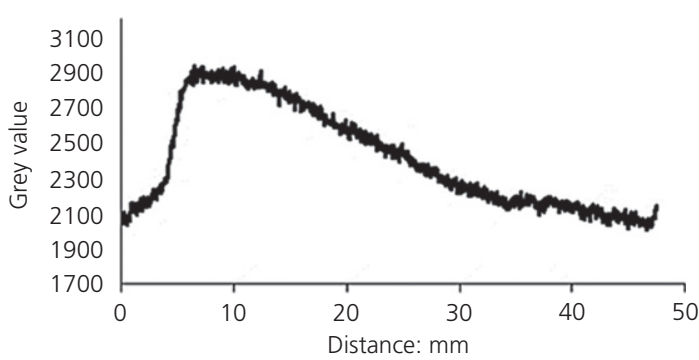

(d)

Figure 6. Autoradiographic images and plot profiles showing the distribution of (a), (b) ${ }^{14} \mathrm{C}$-labelled BSP1 and (c), (d) U(VI) in OPC/GGBS amended with BSP1

is negligible when compared to the concentration of $\mathrm{Ni}(\mathrm{OH})_{3}{ }^{-}$.

The baseline solubility of U(VI), $6 \cdot 1 \times 10^{-7} \pm 5 \cdot 6 \times 10^{-8}$ and $1.4 \times 10^{-6} \pm 1.3 \times 10^{-6} \mathrm{M}$ for OPC/PFA and OPC/GGBS water, respectively, fits well with the results obtained previously by Ewart et al. (1992) and Baston et al. (1993). Similar concentrations can be obtained from thermodynamic modelling, with calcium uranate as the solubility controlling phase $\left(2.6 \times 10^{-6} \mathrm{M}\right.$ for the OPC/PFA water). The solubility enhancement observed with commercial SP in the present study (Figure 2) is comparable to the values reported by Clacher et al. (2011) in a saturated solution of calcium hydroxide, showing an increase of three orders of magnitude upon the addition of $1 \%$ ADVA Cast 551.

Rogers et al. (1989) reported the formation of unidentate complexes of $\mathrm{UO}_{2}{ }^{2+}$ with a PEG molecule (hexaethylene glycol) as well as with a 12-crown-4 ether. They observed an internal hydrogen bond between the oxygen atoms in positions $\mathrm{O} 5$ and O11, causing cyclising of the PEG molecule, which adopts a configuration similar to the crown ether complex. More recently, Servaes et al. (2004) investigated the spectral properties of uranyl complexes with PEG-200, PEG-300 and PEG400 in acetonitrile and propylene carbonate solutions. Changes in the luminescent properties of the uranium indicate that, for the longer PEG chains (PEG-300 and 400), inclusion complexes were formed, whereas for smaller chains, the organic molecule coordinates to the uranyl ion through its second coordination sphere. Despite the extensive use of crown ethers for the separation of lanthanide and actinide mixtures (Servaes et al., 2004), as well as the use of PEG-aqueous biphasic systems for similar purposes (Chen et al., 2005), there are few data describing stability constants for the coordination of $\mathrm{UO}_{2}{ }^{2+}$ with either crown ethers or PEG molecules in aqueous media. The only available formation energies or stability constants for U(VI) with crown ethers have been reported in organic solutions (Rounaghi and Heydari, 2008; Rounaghi and Kakhki, 2009). The published stability constants (Rounaghi and Kakhki, 2009) range between $\log K=2.6$ and 4.6 at $25^{\circ} \mathrm{C}$; therefore, these values were used to estimate a conditional stability constant for the complexation of U(VI) by the SP. Applying the same assumptions as for modelling the behaviour of $\mathrm{Ni}$, that the uranyl-SP complex is stabilised by two $\mathrm{OH}^{-}$ groups and with $\log K=2 \cdot 6$, the predicted concentration of the complex in solution would be negligible in both OPC/PFA and OPC/GGBS. It would be necessary to increase the conditional stability constant to $\log K=23.5$ in order to reproduce uranium concentrations in agreement with the values observed experimentally (Figures 2(a) and 2(c)).

The baseline solubility of $\mathrm{Pu}(\mathrm{IV})$ obtained in the present study fits well with values reported previously in concrete-water at pH 12 (Greenfield et al., 1998). Thermodynamic modelling (JChess code; van der Lee and De Windt (2002) and Hatches, version 20), considering only the formation of an amorphous solid, plutonium (IV) hydroxide $\mathrm{Pu}(\mathrm{OH})_{4(\mathrm{~s})}$ with $\log$ $K_{\mathrm{sp}}=-1 \cdot 64$, gives a predicted concentration in both cement 
waters of $1.2 \times 10^{-9} \mathrm{M}$, with $\mathrm{Pu}(\mathrm{OH})_{4(\mathrm{aq})}$ the dominant species in solution. Altmaier et al. (2008) studied the behaviour of $\mathrm{Pu}(\mathrm{IV})$ in diverse media and suggested that the formation of ternary species stabilised by $\mathrm{Ca}^{2+}$, such as $\mathrm{Ca}_{4}\left[\mathrm{Pu}(\mathrm{OH})_{8}\right]^{4+}$, is only possible at higher concentrations of calcium, between 2 and $4 \mathrm{M}$.

Whereas the commercial SPs have limited effect on the solubility of $\mathrm{Pu}(\mathrm{IV})$ under pre-addition conditions, the addition of $0.5 \% \mathrm{w} / \mathrm{w} \mathrm{SP}$ in the cement-equilibrated water causes an enhancement in $\mathrm{Pu}$ solubility of between two and three orders of magnitude. This increase is comparable to the enhancement observed by Greenfield et al. (1998). These authors tested the effect of a similar polymer at two concentration levels, $0.05 \%$ and $5 \% \mathrm{w} / \mathrm{w}$, observing concentrations of $\mathrm{Pu}$ in concrete water at $\mathrm{pH} 12$ of $2 \times 10^{-8}$ and $6 \times 10^{-6} \mathrm{M}$, respectively. Similar increases in $\mathrm{Pu}(\mathrm{IV})$ solubility were measured in saturated calcium hydroxide in the presence of ADVA Cast 551, going from a baseline solubility of $1.2 \times 10^{-10}$ to $2.2 \times 10^{-7} \mathrm{M}$ with $1 \%$ SP (Clacher et al., 2011). Although no results could be found in the literature for the solubility of $\mathrm{Pu}(\mathrm{IV})$ in the presence of PCE-SP under post-addition conditions, the work of Kitamura et al. (2013) on Th(IV) showed only a slight increase in solubility from $\sim 2 \times 10^{-10} \mathrm{M}$ to around $10^{-9} \mathrm{M}$ with 1000 ppm TOC leached from an OPC matrix.

No stability constants could be found in the literature for the complexation of $\mathrm{Pu}(\mathrm{IV})$ with PEG or crown ethers; therefore, alternative approaches have been adopted in order to reproduce experimental results. Greenfield et al. (1998) investigated the complexation of the polycarboxylic acid polymer HS-700 with $\mathrm{Pu}(\mathrm{IV})$ at $\mathrm{pH}$ 12. In order to fit the experimental results, these authors considered that complexation with organic ligands at high $\mathrm{pH}$ would involve hydroxyl complexes in solution, $\mathrm{Pu}(\mathrm{OH})_{4(\mathrm{aq})}$ in the case of $\mathrm{Pu}(\mathrm{IV})$, and that the complexation will cause displacement of one or more of the hydroxyl groups on the polymer. The structure of the HS-700 polymer is very similar to the structure of the SP used in the present work, the main difference being the length of the side chains. The calculations carried out by Greenfield et al. (1998) assumed that complexation occurs through the adjacent carboxylic groups, that two types of complexes form (monodentate and bidentate) and that the side chains on the HS-700 contained only one $-\left(\mathrm{OCH}_{2} \mathrm{CH}_{2}\right)$ - fragment. It is noted that the PEG chains on the BSP1 contain 15 of these ether units and this number might well be higher for the commercial SPs, COM1-COM4. Therefore, considering an average molecular weight of $16000 \mathrm{~g} / \mathrm{mol}$, as determined by size exclusion chromatography (Isaacs, 2017) for COM1, and a PEG chain with $-\left(\mathrm{OCH}_{2} \mathrm{CH}_{2}\right)_{n^{-}} n=15$, the stability constants obtained for COM1 in OPC/PFA are $\log K_{\text {monodent }}=6 \cdot 3$ and $\log$ $K_{\text {bident }}=4.9$ for the reaction

1. $\mathrm{Pu}(\mathrm{OH})_{4}+\mathrm{Lig} \leftrightarrow \mathrm{Pu}(\mathrm{OH})_{4-x} \mathrm{Lig}+x \mathrm{OH}^{-}$ where $x=1$ for monodentate and 2 for the bidentate binding. The actual length of the PEG moiety is longer $(n \geq 15)$ in the commercial COM1 than assumed in the calculations of Greenfield et al. (1998) and, therefore, the concentration of binding sites has been overestimated for the purpose of the calculations. Nevertheless, the resulting stability constants are three orders of magnitude higher than the values obtained previously $\left(\log K_{\text {monodent }}=3 \cdot 3\right.$ and $\log K_{\text {bident }}=1 \cdot 6$ ). This would suggest that a different mechanism of complexation is responsible for the enhancement of $\mathrm{Pu}(\mathrm{IV})$ solubility other than simply monodentate and bidentate interaction with the carboxylic groups. It would appear that the longer PEG chains used for both the synthesis of the commercial products (200-2000 amu) and the bespoke BSP1 (950 amu) provide the molecule with the freedom to change its steric configuration and furnish additional binding sites.

The measured baseline solubility of Am(III) compares well with the values reported by Greenfield et al. (1998) in concrete water $\left(5 \times 10^{-11} \mathrm{M}\right)$ and Kitamura et al. (2013) in OPC systems (ca. $\left.10^{-11} \mathrm{M}\right)$. The predicted baseline solubility for both OPC/PFA and OPC/GGBS media with crystalline americium (III) hydroxide phase $\mathrm{Am}(\mathrm{OH})_{3(\mathrm{cr})}$ as the solubility controlling phase was $2 \cdot 4 \times 10^{-11} \mathrm{M}$, which also matches the experimental results (Figure 4). An enhancement of Am solubility was observed only with the commercial SP, and then only under post-addition conditions. No enhancement was found when the SPs were added to the cement prior to leaching. The results reported here agree with those of Kitamura et al. (2013) for Am under similar conditions to the preaddition method employed in the present work, notwithstanding the fact that these authors studied OPC pore water and a polycarboxylic acid polymer SP, SP8LS, at the higher loading of $1 \% \mathrm{w} / \mathrm{w}$. Kitamura et al. (2013) found that the concentration of Am in solution, both with and without SP, ranged from $10^{-9}$ to $10^{-8} \mathrm{M}$ after filtration through $0.45 \mu \mathrm{m}$ filters, whereas when using $10 \mathrm{kDa}$ membranes, the solubilities fell to around $10^{-11} \mathrm{M}$. The results obtained in the present work correspond to the latter, suggesting that the sample preparation method used here ensured efficient removal of colloidal particles.

Kitamura et al. (2013) used gluconic acid to model the interaction of the PCE type SP with Am; however, the thermodynamic calculations did not show any contribution of the organic compound (as $\mathrm{AmH}_{2} \mathrm{GLU}^{-}$) to the total solubility of $\mathrm{Am}$, which was predicted to lie in the range $5.4 \times 10^{-11}$ $4.3 \times 10^{-9} \mathrm{M}$. Therefore, a decision was made to apply the model proposed by Greenfield et al. (1998), which provided stability constants for the monodentate and bidentate complexes of $3 \cdot 12$ and $1 \cdot 72$, respectively, for the reaction in Equation 2

2. $A m(\mathrm{OH})_{3}+\mathrm{Lig} \leftrightarrow \mathrm{Am}(\mathrm{OH})_{3-x} \mathrm{Lig}+x \mathrm{OH}^{-}$ 
The values match well with the constants obtained by Greenfield et al. (1998), that is $3 \cdot 3$ and $1 \cdot 9$, respectively, although it should be noted that the values obtained both here and by Greenfield et al. (1998) result from direct fitting of the experimental data and do not provide confirmation of the complexation mechanism.

Previous research that demonstrated the solubilising effect of ADVA Cast 551 on Ni(II), Am(III), Th(IV), Pu(IV) and U(VI) (Angus et al., 2010; Clacher et al., 2011, 2013a, 2013b; Young et al., 2013) was constrained by the fact that the composition of both the SP itself and adjuncts was not disclosed by the manufacturer. The results described above show clearly that the purified BSP1, dialysed through $1200 \mathrm{MW}$ membranes, causes a much smaller increase in radionuclide solubility than commercial SP products. As adjuncts (de-foaming agent, biocide and viscosity modifiers) appear to have no effect on solubility when used in isolation, the differences are attributed to the presence of polymer fragments or residues from the industrial polymerisation process. Another difference between the commercial and purified SP is the length of the PEG chain, as longer molecules (200-2000 amu) provide more steric freedom for complexation with the radionuclides by adopting a configuration similar to a crown ether.

Finally, although the experimental data could be fitted satisfactorily using conditional stability constants for the formation of monodentate and bidentate complexes of PCE SP with Pu and Am, detailed spectroscopic studies are required to determine the structure of the complexes responsible for the solubility enhancements.

\section{Radionuclide incorporation}

The addition of SP caused an increase in the amount of bleed water produced by the cements; the increase is much higher for OPC/GGBS than for OPC/PFA blends, as noted previously (Young, 2012; Young et al., 2013). The SP also causes a significant reduction in porosity of OPC/GGBS blocks, which is not observed in the case of OPC/PFA (Isaacs, 2017). When the OPC/GGBS blocks were sectioned, a clear zonation was found, with smaller particles concentrated at the bottom of the block (Figure S6). It was also apparent that, although all the blocks initially contained the same amount of cement (95-110 g), OPC/GGBS containing SP forms a more compact matrix. It is well known that SPs prevent agglomeration, resulting in retardation of the process of flocculation of clinker particles and hydrates (Zingg et al., 2008). Moreover, SPs can prompt bleed (Łaźniewska-Piekarczyk, 2015; Young et al., 2013), although the amount of bleed may be reduced by modification of the grout formulation, in particular by reduction of the water content, and also by up-scaling of the mixes (Isaacs et al., 2017; Josserand and de Larrard, 2002). In the case of the OPC/PFA blocks, no zonation was observed and the specimens showed a more even distribution of particles than the OPC/GGBS blocks, which led in turn to a homogeneous distribution of the pores. In OPC/GGBS blends, larger particles rise during mixing, resulting in higher porosity and an accumulation of both SP and radionuclides at the top of the block (Figure 6). The propensity of the commercial SPs and BSP1 to cause bleed generally matches the behaviour of the same compounds found in the solubility studies, with enhanced radionuclide mobility found for the commercial products. When the commercial SP, COM3, was dialysed, following the same procedure as for BSP1, prior to mixing with the grouts and radionuclides, the quantity of radionuclide present in the bleed was very low $(0-0.003 \%$ of the original radionuclide load) and comparable to that observed for the purified BSP1. These results reinforce the hypothesis that the monomer present in the commercial SP is the component responsible for the solubilisation of the radionuclides and not the SP polymers themselves.

A study by Fujita et al. (2008) concluded that more than $90 \%$ of the polycarboxylate SP remains in the cement and that only molecules of lower molecular weight, either residual monomers or degradation products, are leached into the curing water. In order to test this hypothesis and to assess the mobility of both the SP polymers and their monomers, experiments were repeated using ${ }^{14} \mathrm{C}$-labelled BSP1, ${ }^{14} \mathrm{C}$-labelled PEGMA and ${ }^{14} \mathrm{C}$-methacrylate (MAA). Autoradiographic images (Figure S7) show that, whereas PEGMA is distributed homogeneously within the OPC/GGBS matrix, MAA and non-purified SP accumulate at the top of the blocks. This may be related to the polarity of the monomers - the greater hydrophobicity of the PEGMA chains resulting in stronger interaction with the solid particles. The MAA, owing to its higher polarity, is more evenly distributed in the aqueous phase and migrates to the top of the blocks. Once more, this effect is reflected in the distribution of the radionuclides. Thus, purified BSP1 or PEGMA does not cause any redistribution of the radionuclides within the cement, whereas MAA and non-purified BSP1 lead to accumulation of the radionuclides near the top surface and higher concentrations in the bleed water. No such effect was observed for OPC/PFA, where the distribution of the labelled monomers was homogeneous. It has been previously reported that the unburnt carbon content of the PFA has a tendency to absorb any organic compounds added to cementitious admixtures, such as air-entraining agents (Ahmed et al., 2014; Bapat, 2012). The high affinity of the PFA particles for organic compounds in comparison with GGBS (see LOI data in the Supplementary Material) could explain the homogeneous distribution of the radiolabelled monomers observed for the OPC/PFA blocks. The experiments with ${ }^{14} \mathrm{C}$-labelled compounds and comparison of results for purified and non-purified SPs suggest that the smaller and more polar components in the SP products are directly linked to the increase in bleed and radionuclide mobility observed.

Despite the evidence linking SP to increased solubility and bleed, the presence of SP appears to have no discernible effect 
on the mobility of radionuclides once the paste has hardened, as demonstrated by leaching, diffusion and adsorption experiments (Wieland et al., 2014). Samples used for the bleed experiments were subjected to monolithic leach tests in accordance with BS EN 15863 (BSI, 2012) (36 d leach), as well as granular 'HazWac' leach tests ( $24 \mathrm{~h}$ leach), following BS EN 12457-3:2002 (BSI, 2002). No evidence of radionuclide leaching was detected for either test in the grouts containing COM1-COM4 or BSP1 (Isaacs, 2017; NDA, 2015). Radial through-diffusion studies, of the type described by FelipeSotelo et al. (2014), showed no breakthrough of $\mathrm{Ni}(\mathrm{II})$, $\mathrm{Am}(\mathrm{III}), \mathrm{Pu}(\mathrm{IV})$ or U(VI) in OPC/GGBS or OPC/PFA cement blocks containing SP after 6 months (NDA, 2015). Autoradiographic images confirmed that the radionuclides accumulate on the surface of the central well and do not penetrate the cement (a through-diffusion experiment involving $\mathrm{Pu}(\mathrm{IV})$ is shown as an example in Figure 7).

\section{Conclusions}

The addition of $0.5 \% \mathrm{w} / \mathrm{w}$ commercial SPs to cementequilibrated waters causes a significant increase in the solubility of four radionuclides, covering oxidation states from (II) to (VI). However, when the SPs are present at much lower levels, corresponding to the concentrations anticipated in actual cement pore waters, the solubility enhancement is negligible. Therefore, previous studies of radionuclide solubility enhancement using SP in free solution (post-addition conditions) provide unrealistic overestimates of the effect of SPs on radionuclide solubility. Confirmation that the bulk of the SP is bound to the cement would account for the fact that these additives do not appear to promote radionuclide migration through intact cement monoliths.

Various adjuncts used to increase shelf-life and workability also show no effect on radionuclide solubility when tested in isolation. Comparison of commercial products with the behaviour of a bespoke synthesised and purified SP suggests that the agents responsible for radionuclide complexation are not the SP polymers themselves but rather lower molecular weight organics in the form of residual monomers or molecular fragments arising from degradation.

The use of SP to make OPC/GGBS grouts, in particular, results in increased bleed during cement set and the occurrence of radionuclides in the bleed water. The distribution of $\mathrm{U}, \mathrm{Pu}$ and $\mathrm{Am}$ is inhomogeneous in OPC/GGBS amended with commercial SP and heavily concentrated towards the top of the blocks. Similar blocks produced using OPC/PFA or dialysed SP show a more homogeneous distribution of radionuclides. The segregation of ${ }^{14} \mathrm{C}$-labelled SP and the monomer MAA mirrors that of the radionuclides, indicating that the smaller and more polar components in the SP mixes are directly linked to the increase in bleed and radionuclide mobility.

From the results presented, it would seem that the addition of PCE SP to grouts used for waste encapsulation will have a limited effect on the mobility of radionuclides owing to retention of the polymer by the cement matrix. However, the purity of the SP is a factor that should be considered when assessing the applicability of a given product as a waste encapsulation grout. Further studies are required to assess the longer term effects of SP and their potential degradation products in cement. It is also necessary to obtain a better understanding of the interaction mechanisms in ternary radionuclide-SP-cement systems. Molecular fractionation and uptake experiments using radiolabelled compounds, targeting specific phases in the cement paste, would provide information on the chemical identity of the moiety or functional group(s) of the SP responsible for the solubilisation effect on radionuclides as well as the mechanism of SP retention on the cement surface.

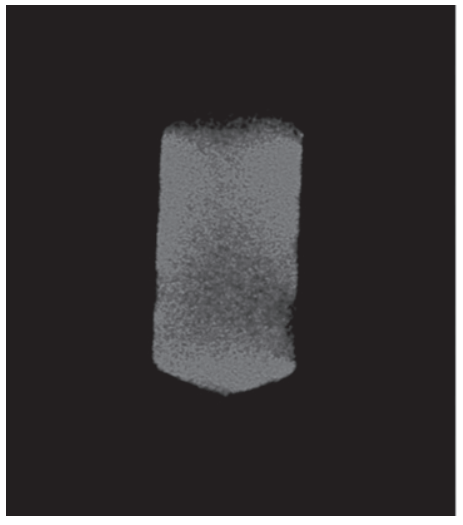

(a)

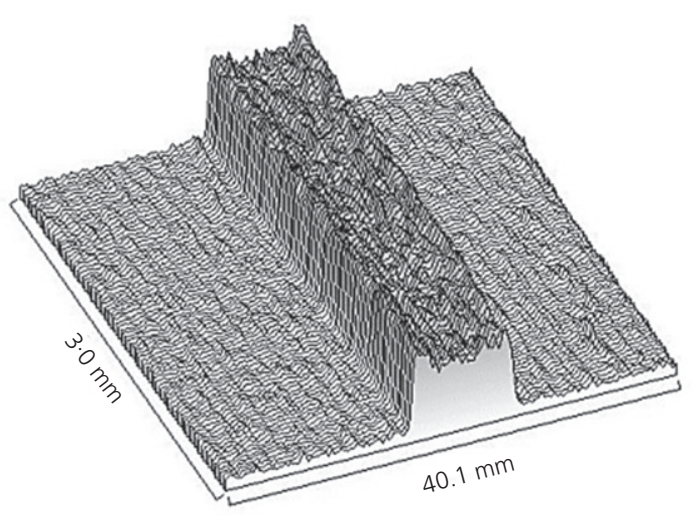

(b)

Figure 7. (a) Autoradiographic image of the distribution of Pu(IV) in an OPC/GGBS cement block amended with COM4, used for a through-diffusion experiment in radial configuration and (b) surface plot of the same block 


\section{Acknowledgements}

The authors would like to thank the Nuclear Decommissioning Authority (NDA) for funding this research, including a PhD bursary for $\mathrm{M}$. Isaacs. The authors also acknowledge the valuable contributions of Drs A. Shelton, S. Williams, R. Beard and M. Beard of Radioactive Waste Management (RWM) Ltd and J. Holt (Loughborough University). J. Kuva and Dr M. Siitari-Kauppi of the University of Helsinki are thanked for their assistance with the porosity measurements.

\section{REFERENCES}

Ahmed ZT, Hand DW, Watkins MK and Sutter LL (2014) Combined adsorption isotherms for measuring the adsorption capacity of fly ash in concrete. ACS Sustainable Chemistry \& Engineering 2(4): 614-620.

Altmaier M, Neck V and Fanghänel T (2008) Solubility of Zr(IV), Th(IV) and $\mathrm{Pu}(\mathrm{IV})$ hydrous oxides in $\mathrm{CaCl}_{2}$ solutions and the formation of ternary Ca-M(IV)-OH complexes. Radiochimica Acta 96(9-11): $541-550$.

Angus MJ, Godfrey IH, Hayes M and Foster S (2010) Managing change in the supply of cement powders for radioactive waste encapsulation - twenty years of operational experience. Proceedings of Waste Management 2010 Conference, Phoenix, AZ, USA.

Balasubramanian D and Chandani B (1983) Poly(ethylene glycol) a poor chemist's crown. Journal of Chemical Education 60(1): 77-78.

Bapat JD (2012) Mineral Admixtures in Cement and Concrete. CRC Press (Taylor \& Francis Group), Boca Raton, FL, USA

Baston G, Brownsword M, Cross J et al. (1993) The Solubility of Uranium in Cementitious Near-Field Chemical Conditions. AEA Technology, Harwell, UK, Report NSS/R222.

BSI (2000) BS EN 197-1:2000: Cement part 1: definition, specifications and conformity criteria for common cements. BSI, London, UK.

BSI (2002) BS EN 12457-3:2002: Characterisation of waste - leaching compliance test for leaching of granular waste materials and sludges. BSI, London, UK.

BSI (2005) BS EN 450-1:2005: Fly ash for concrete part 1: definition, specifications and conformity criteria. BSI, London, UK.

BSI (2006) BS EN 15167-1:2006: Gound granulated glast furnace slag for use in concrete, mortar and grout part 1: definitions, specifications and conformity criteria. BSI, London, UK.

BSI (2012) BS EN 15863:2012: Characterization of waste - leaching behaviour test for basic characterisation - dynamic monolithic leaching test with periodic leachant renewal under fixed test conditions. BSI, London, UK.

Cann GM and Orr RM (2010) A Technical Specification for Portland Cement, Blast Furnace Slag and Fly Ash Powder for Use in the Encapsulation/Immobilisation of Radioactive Waste Materials (8th Revision). National Nuclear Laboratory (NNL), Sellafield, UK, NNL Report for NDA, NNL(10)10653.

Chen J, Spear S, Huddleston J and Rogers R (2005) Polyethylene glycol and solutions of polyethylene glycol as green reaction media. Green Chemistry 7(1): 64-82.

Clacher A, Cowper M, Swanton S and Holton D (2011) Effect of ADVA Cast 551 on the Solubility of Plutonium(IV) and Uranium(VI). NDA, Harwell, UK. Serco Report, NPO003662. See http://rwm. nda.gov.uk/publication.Effect-of-ADVA-Cast-551-on-the-solubilityof-plutonium-IV-and-uranium-vi-report-to-nda-rwmd-March-2011 (accessed 15/10/2017).

Clacher A, Marshall T and Swanton S (2013a) Solubility Studies: Effect of ADVA Cast 551 at Low Concentration. NDA, Harwell, UK.
Amec Report NPO004236/RWM005477. See http://rwm.nda.gov. uk/publication/amec_ts_004249_001-issue-04 (accessed 15/10/2017).

Clacher A, Baston G, Glasser F, Jauffret G and Swanton S (2013b) Effect of ADVA Cast 551 Superplasticiser on Radionuclide Solubility. NDA, Harwell, UK. Amec Report RWM005244B. See http://rwm. nda.gov.uk/publication/effects-of-superplasticiser-on-radionuclidesolubility (accessed 15/10/2017).

Defra, BERR, Welsh Assembly Goverment, Northern Ireland Department of the Environment (2008) Managing Radioactive Waste Safely: A Framework for Implementing Geological Disposal. Department for Environment, Food \& Rural Affairs, York, UK. See http://www.gov.uk/government/publications/managing-radioactivewaste-safely-a-framework-for-implementing-geological-disposal (accessed 15/10/2017).

Ewart F, Smith-Briggs J, Thomason H and Williams S (1992) The solubility of actinides in a cementitious near-field environment. Waste Management 12(2-3): 241-252.

Felipe-Sotelo M, Hinchliff J, Drury D et al. (2014) Radial diffusion of radiocaesium and radioiodide through cementitious backfill. Physics and Chemistry of the Earth 70-71(1): 60-70.

Fujita H, Haga K, Shibata M and Mihara M (2008) Concentration and molecular weight of superplasticizer contained in pore solution extracted from hardened cement pastes. Journal of Advanced Concrete Technology 6(3): 389-395.

Gaona X, Montoya V, Colas E, Grive M and Duro L (2008) Review of the complexation of tetravalent actinides by ISA and gluconate under alkaline to hyperalkaline conditions. Journal of Contaminant Hydrology 102(3-4): 217-227.

García DM, Escobar JL, Bada N et al. (2004) Synthesis and characterization of poly(methacrylic acid) hydrogels for metoclopramide delivery. European Polymer Journal 40(8): 1637-1643.

Greenfield B, llett D, Ito M et al. (1998) The effect of cement additives on radionuclide solubilities. Radiochimica Acta 82(S1): 27-32.

Hatches-Database (2016) HATCHES Thermodynamic Database: $A M E C$. RWM, Harwell, UK. See http://www.hatches-database. $\mathrm{com} /$ (accessed 03/03/2016).

Isaacs M (2017) Superplasticisers and their Effect on Radionuclides in Cementitious Environments. PhD thesis, Loughborough University, Loughborough, UK.

Isaacs M, Hayes M, Rawlinson S et al. (2017) The processing and product characteristics of a blended cement grout incorporating a polycarboxylate ether superplasticiser. Advances in Cement Research, http://dx.doi.org/10.1680/jadcr.17.00102.

Izatt R, Terry R, Haymore B et al. (1976) Calorimetric titration study of the interaction of several uni- and bivalent cations with 15-crown5,18 -crown- 6 in aqueous solution at $25^{\circ} \mathrm{C}$ and $\mu=0 \cdot 1$. Journal of the American Chemical Society 98(24): 7620-7626.

Josserand L and de Larrard F (2002) Experimental study of scale effect in fresh mortar bleeding. In Innovations and Developments in Concrete Materials and Construction (Dhir RV, Hewlett PC and Csetenyi LJ (eds)). Thomas Telford, London, UK, pp. 819-826, http://dx.doi.org/10.1680/iadicmac.31791.0078.

Kitamura A, Fujiwara K, Mihara M, Cowper M and Kamei G (2013) Thorium and americium solubilities in cement pore water containing superplasticiser compared with thermodynamic calculations. Journal of Radioanalytical and Nuclear Chemistry 298(1): 485-493.

Łaźniewska-Piekarczyk B (2015) Influence of antifoaming admixture type on several properties of high-performance self-compacting concrete. Journal of Materials in Civil Engineering 27(9): 04014247-1-11.

Li J and Kao W (2003) Synthesis of polyethylene glycol (PEG) derivatives and PEGylated-peptide biopolymer conjugates. Biomacromolecules 4(4): 1055-1067. 
McCrohon R and Williams S (1997) Effect of Sikament 10 Superplasticiser on Radionuclide Solubility. NIREX, Harwell, UK, RWMD (97) P038 Issue 1.

NDA (Nuclear Decommissioning Authority) (2010a) Geological Disposal: Package Evolution Status Report. NDA, Harwell, UK, NDA Report NDA/RWMD/031. See http://rwm.nda.gov.uk/publication/ geological-disposal-package-evolution-status-report-december-2010 (accessed 15/10/2017).

NDA (2010b) Geological Disposal: Near-Field Evolution Status Report. NDA, Harwell, UK, NDA Report NDA/RWMD/033. See http://rwm.nda.gov.uk/publication/geological-disposal-nearfield-evolution-status-report-december-2010 (accessed 15/10/2017).

NDA (2010c) Geological Disposal: Radionuclide Behaviour Status Report. NDA, Harwell, UK, NDA Report NDA/RWMD/034. See http:// rwm.nda.gov.uk/publication/geological-disposal-radionuclidebehaviour-status-report-december-2010 (accessed 15/10/2017).

NDA (2013) Geological Disposal: Upstream Optioneering. Overview and Uses of the 6 Cubic Metre Concrete Box. NDA, Harwell, UK, NDA Technical Note no. 18959097. See http://rwm.nda.gov. uk/publication/gd-upstream-optioneering-overview-and-uses-of-the6-cubic-metre-concrete-box (accessed 15/10/2017).

NDA (2015) Solubility Studies in the Presence of Polycarboxylate Ether Superplasticisers. NDA, Harwell, UK, NDA Report WP/B2/7. See http://www.gov.uk/government/publications/solubility-studiesin-the-presence-of-polycarboxylate-ether-superplasticisers (accessed 15/10/2017).

Pilkington N and Stone N (1990) The Solubility and Sorption of Nickel and Niobium under High pH Conditions. NIREX, Harwell, UK, Nirex Report NSS/R186.

Plank J and Hirsch C (2007) Impact of zeta potential of early cement hydration phases on superplasticizer adsorption. Cement and Concrete Research 37(4): 537-542.

Plank J, Pöllmann K, Zouaoui N, Andres P and Schaefer C (2008) Synthesis and performance of methacrylic ester based polycarboxylate superplasticizers possessing hydroxy terminated poly(ethylene glycol) side chains. Cement and Concrete Research 38(10): 1210-1216.

Rogers R, Benning M, Etzenhouser R and Rollins A (1989) Novel unidentate co-ordination of a crown ether and of a polyethylene glycol to uranium(VI). Journal of the Chemical Society, Chemical Communications 20(7): 1586-1588.

Rounaghi G and Heydari S (2008) A thermodynamic study of complex formation between cicyclohexyl-18-crown-6 (DCH18C6) and $\mathrm{La}^{3+}$, $\mathrm{UO}_{2}{ }^{2+}, \mathrm{Ag}^{+}$and $\mathrm{NH}_{4}{ }^{+}$cations in acetonitrile-tetrahydrofuran binary media using conductimetric method. Russian Journal of Coordination Chemistry 34(11): 836-841.

Rounaghi G and Kakhki R (2009) Thermodynamic study of the complex formation between dibenzo-18-crown- 6 and $\mathrm{UO}_{2}{ }^{2+}$ cation in different non-aqueous binary solutions. Journal of Inclusion Phenomena and Macrocyclic Chemistry 63(1): $117-122$.

Salah S and Wang L (2014) Speciation and Solubility Calculations for Waste Relevant Radionuclides in Boom Clay. Studiecentrum voor Kernenegie (SCK)/CEN, Mol, Belgium, SCK-CEN Report SCK-CEN-ER-198.

Servaes K, De Houwer S, Görller-Walrand C and Binnemans K (2004) Spectroscopic properties of uranyl crown ether complexes in non-aqueous solvents. Physical Chemistry Chemical Physics 6(11): 2946-2950.

Sil A and Srivastava A (2004) Studies of the complexation of transition metal ions with macrocyclic compounds in mixed solvents by competitive potentiometry and polarography. Supramolecular Chemistry 16(5): 343-351.

Totten GE, Clinton NA and Matlock PL (1998) Poly(ethylne glycol) and derivatives as phase transfer catalysts. Journal of Supramolecular Science Part C 38(1): 77-142.

van der Lee J and De Windt L (2002) CHESS Tutorial and Cookbook. Updated for Version 3.0. Users Manual LHM/RD/02/13. Ecole des Mines de Paris, Fontainebleau, France.

Wieland E, Lothenbach B, Glaus MA, Thoenen T and Schwyn B (2014) Influence of superplasticizers on the long-term properties of cement pastes and possible impact on radionuclide uptake in a cement-based repository for radioactive waste. Applied Geochemistry 49(1): 126-142.

Young A (2012) The Stability of Cement Superplasticiser and Its Effect on Radionuclide Behaviour. $\mathrm{PhD}$ thesis, Loughborough University, Loughborough, UK.

Young A, Milodowski A, Warwick P and Read D (2013) Behaviour of radionuclides in the presence of superplasticiser. Advances in Cement Research 25(1): 32-43, http://dx.doi.org/10.1680/adcr.12. 00032.

Yu Y, Liu J, Ran Q, Qiao M and Gao N (2013) Interfacial interaction between comb-like copolymer dispersants and tricalcium silicate. Magazine of Concrete Research 65(3): 202-208, http://dx.doi. org/10.1680/macr.12.00058.

Zingg A, Holzer L, Kaech A et al. (2008) The microstructure of dispersed and non-dispersed fresh cement pastes - new insight by cryo-microscopy. Cement and Concrete Research 38(4): 522-529.

\section{How can you contribute?}

To discuss this paper, please submit up to 500 words to the editor at journals@ice.org.uk. Your contribution will be forwarded to the author(s) for a reply and, if considered appropriate by the editorial board, it will be published as a discussion in a future issue of the journal. 